\title{
Interpretative strategies for lung function tests
}

\author{
R. Pellegrino, G. Viegi, V. Brusasco, R.O. Crapo, F. Burgos, R. Casaburi, A. Coates, \\ C.P.M. van der Grinten, P. Gustafsson, J. Hankinson, R. Jensen, D.C. Johnson, \\ N. MacIntyre, R. McKay, M.R. Miller, D. Navajas, O.F. Pedersen and J. Wanger
}

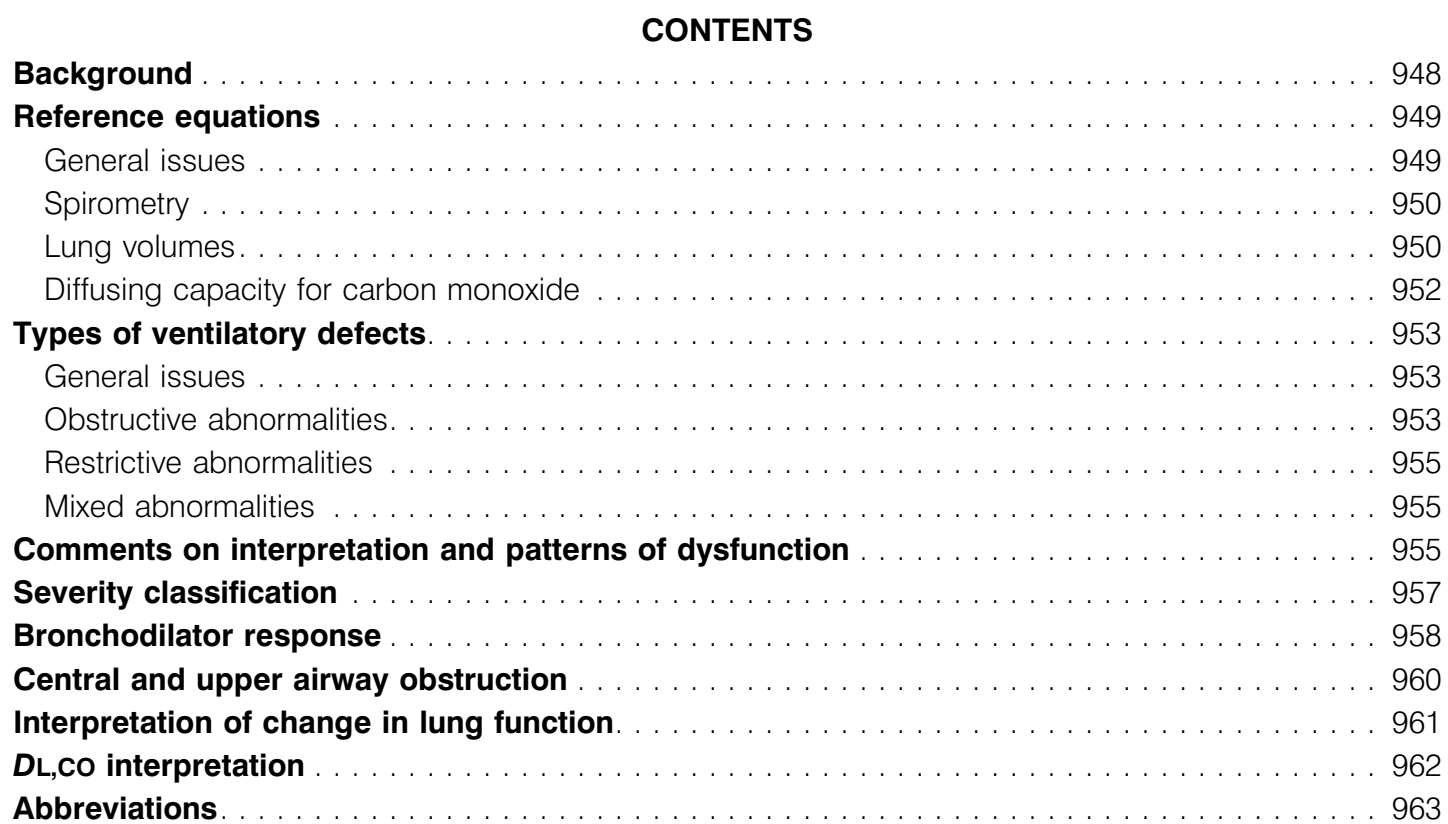

KEYWORDS: Bronchodilator, diffusing capacity, lung volume measurements, spirometry, reference values, ventilatory defects

\section{BACKGROUND}

This section is written to provide guidance in interpreting pulmonary function tests (PFTs) to medical directors of hospital-based laboratories that perform PFTs, and physicians who are responsible for interpreting the results of PFTs most commonly ordered for clinical purposes. Specifically, this section addresses the interpretation of spirometry, bronchodilator response, carbon monoxide diffusing capacity $(D \mathrm{~L}, \mathrm{CO})$ and lung volumes.
The sources of variation in lung function testing and technical aspects of spirometry, lung volume measurements and DL,CO measurement have been considered in other documents published in this series of Task Force reports [1-4] and in the American Thoracic Society (ATS) interpretative strategies document [5].

An interpretation begins with a review and comment on test quality. Tests that are less than optimal may still contain useful information, but interpreters should identify the problems and the

Previous articles in this series: No. 1: Miller MR, Crapo R, Hankinson J, et al. General considerations for lung function testing. Eur Respir J 2005; 26: 153-161. No. 2: Miller MR, Hankinson J, Brusasco V, et al. Standardisation of spirometry. Eur Respir J 2005; 26: 319-338. No. 3: Wanger J, Clausen JL, Coates A, et al. Standardisation of the measurement of lung volumes. Eur Respir J 2005; 26: 511-522. No. 4: Maclntyre N, Crapo R0, Viegi G, et al. Standardisation of the single-breath determination of carbon monoxide uptake in the lung. Eur Respir J 2005; 26: 720-735.

AFFILIATIONS

For affiliations, please see Acknowledgements section.

CORRESPONDENCE

V. Brusasco

Internal Medicine University of Genoa V.le Benedetto XV, 6 Genova I-16132 Italy

Fax: 390103537690 E-mail: vito.brusasco@unige.it

Received:

March 242005

Accepted:

April 052005 
direction and magnitude of the potential errors. Omitting the quality review and relying only on numerical results for clinical decision making is a common mistake, which is more easily made by those who are dependent upon computer interpretations.

Once quality has been assured, the next steps involve a series of comparisons [6] that include comparisons of test results with reference values based on healthy subjects [5], comparisons with known disease or abnormal physiological patterns (i.e. obstruction and restriction), and comparisons with self, a rather formal term for evaluating change in an individual patient. A final step in the lung function report is to answer the clinical question that prompted the test.

Poor choices made during these preparatory steps increase the risk of misclassification, i.e. a falsely negative or falsely positive interpretation for a lung function abnormality or a change in lung function. Patients whose results are near the thresholds of abnormality are at a greatest risk of misclassification.

\section{REFERENCE EQUATIONS}

\section{General issues}

Interpretation of PFTs is usually based on comparisons of data measured in an individual patient or subject with reference (predicted) values based on healthy subjects. Predicted values should be obtained from studies of "normal" or "healthy" subjects with the same anthropometric (e.g. sex, age and height) and, where relevant, ethnic characteristics of the patient being tested. Ideally, reference values are calculated with equations derived from measurements observed in a representative sample of healthy subjects in a general population. Reference equations can also be derived from large groups of volunteers, provided that criteria for normal selection and proper distribution of anthropometric characteristics are satisfied. Criteria to define subjects as "normal" or healthy have been discussed in previous ATS and European Respiratory Society (ERS) statements [5, 7, 8].

Height and weight should be measured for each patient at the time of testing; technicians should not rely on stated height or weight. Height should be measured with a stadiometer, with shoes off, using standard techniques (patient standing erect with the head in the Frankfort horizontal plane) [9]. When height cannot be measured, options include using stated height or estimating height from arm span, as indicated in a previous document from this series and other publications $[1,10,11]$.

Specific recommendations for selecting reference values to be used in any lung function laboratory have also been discussed [3]. These include the following: matching age-range, anthropometric, race/ethnic, socio-economic and environmental characteristics between subjects investigated by the laboratory and the reference population from which the prediction equations have been drawn; using similar instruments and lung function protocols in the reference population as in the laboratory; and using reference values derived by valid and biologically meaningful statistical models, taking into account the dependence of lung function with age. If possible, all parameters should be taken from the same reference source. For example, forced vital capacity (FVC), forced expiratory volume in one second (FEV1), and FEV1/FVC should come from the same reference source.
The subjects being tested should be asked to identify their own race/ethnic group, and race/ethnic-specific reference equations should be used whenever possible. If such equations are not available or are unsuitable for a particular setting, a race/ ethnic adjustment factor based on published data may be used for lung volumes. The use of adjustment factors is not as good as specific race/ethnic equations [12]. An example of adjustment factors is the finding that populations using standing height as the measure of size tend to overpredict values measured in Black subjects by $\sim 12 \%$ for total lung capacity (TLC), FEV1 and FVC, and by $\sim 7 \%$ for functional residual capacity (FRC) and residual volume (RV) [5]. A race/ethnic adjustment factor of 0.94 is also recommended for Asian Americans based on two recent publications [13, 14]. Such adjustment factors should not be applied to the FEV1/FVC or FEV1/vital capacity (VC) ratios. The use of sitting height does not completely account for race/ethnic differences in pulmonary function [15]. If a race adjustment factor is used, a statement should be included in the report, along with the race adjustment value used.

Differences in the evaluation of lung function using different sets of reference equations have been documented [16, 17]. Ideally, spirometric reference values should be derived from a population similar to the individual subject using the same kind of instrument and testing procedure.

There have been recommendations to compare selected reference equations with measurements performed on a representative sample of healthy subjects tested in each laboratory. The reference equation that provides the sum of residuals (observed - predicted computed for each adult subject, or log observed - log predicted for each subject in the paediatric age range) closest to zero will be the most appropriate for that laboratory [7]. However, for spirometry, a relatively large number of subjects (i.e. $n=100$ ) is necessary to be confident that a significant difference between the published reference equations and the values from the local community does not exist [18]. Therefore, the suggestion is impractical for most laboratories.

When using a set of reference equations, extrapolation beyond the size and age of investigated subjects should be avoided [7]. If a patient's age or height is outside the limits of the reference population, a statement in the interpretation should indicate that an extrapolation has been made.

Publications on reference equations should include explicit definitions of the upper and lower limits of the normal range, or provide information to allow the reader to calculate a lower range [5]. For each lung function index, values below the 5th percentile of the frequency distribution of values measured in the reference population are considered to be below the expected "normal range" [5]. If the reference data have a normal distribution, the lower 5 th percentile can be estimated as the $95 \%$ confidence interval using Gaussian statistics. If the distribution is skewed, the lower limit should be estimated with a nonparametric technique, such as the 95th percentile. The practice of using $80 \%$ predicted as a fixed value for the lower limit of normal may be acceptable in children, but can lead to important errors when interpreting lung function in adults [5]. The practice of using 0.70 as a lower limit of the 
FEV1/FVC ratio results in a significant number of falsepositive results in males aged $>40 \mathrm{yrs}$ and females $>50 \mathrm{yrs}$ [12], as well as in a risk of overdiagnosis of chronic obstructive pulmonary diseases (COPD) in asymptomatic elderly neversmokers [19]. This discussion has been focused on the lower limit of the reference range. Upper limits are appropriate where the variable can be either too high or too low. Such variables include TLC, RV/TLC and DL,CO. As equipment and techniques for lung function testing improve, advanced mathematical models to describe lung function data are implemented. Furthermore, the characteristics of the populations of "normal" subjects, with respect to nutrition, health status, environmental conditions and other factors, evolve (a phenomenon also described as "cohort effect"). Consideration should be given to updating reference equations on a regular basis, e.g. every $10 \mathrm{yrs}$, taking into account the applicability of the newer reference equations and the effect on interpretation of longitudinal patient follow-up.

Manufacturers should also provide software that allows users to easily select among a panel of reference equations. They should also allow easy insertion of new equations. The reference values used should be documented on every pulmonary function report with the first author's last name (or organisation) and the date of publication.

\section{Spirometry}

The European Community for Coal and Steel (ECCS) [8, 20] and the ATS $[5,21]$ have both published comprehensive listings of published reference equations for spirometry. A number of additional studies on lung function reference values, dealing with a variety of ethnic/race groups and age ranges, have been published in the last 10 yrs [12, 14, 17, 22, 23].

Spirometric reference equations are usually derived from cross-sectional studies and are subject to "cohort effect". Few authors have published longitudinal equations covering ages from childhood to the elderly [24-26], and there are few published sets of equations that cover volume and flow indices over a wide range of ages [27, 28]. Table 1 includes reference equations published from 1995 to August 2004. The table was created from known equations and a MEDLINE search using the keywords "reference equations" and "spirometry". Its purpose is to recognise and encourage the continuing interest of worldwide researchers in deriving and using reference equations.

In the USA, ethnically appropriate National Health and Nutrition Examination Survey (NHANES) III reference equations are recommended for those aged 8-80 yrs [12]. For children aged $<8$ yrs, the equations of WANG et al. [29] are recommended. Other prediction equations may be used if there are valid reasons for the choice. In Europe, the combined reference equations published in the 1993 ERS statement [8] are often used for people aged 18-70 yrs, with a height range of $155-195 \mathrm{~cm}$ in males, and $145-180 \mathrm{~cm}$ in females, and those from QUANJER et al. [30] in paediatric ages. Currently, this committe does not recommend any specific set of equations for use in Europe, but suggests the need for a new Europe-wide study to derive updated reference equations for lung function.

\section{Lung volumes}

Lung volumes are related to body size, and standing height is the most important correlating variable. In children and adolescents, lung growth appears to lag behind the increase in standing height during the growth spurt, and there is a shift in the relationship between lung volume and height during adolescence [31, 32]. Height growth in young males between 12.5 and 18 yrs of age peaks $\sim 1$ yr before the growth rate of weight and FVC, and $\sim 1.5$ yrs before the growth rate of maximum flow at $50 \%$ FVC. In young females, growth rates of all spirometric indices decrease over the same age range. Using simple allometric relationships between stature and lung volumes, volume predictions are too high in the youngest age group and too low in the oldest adolescents.

Furthermore, for the same standing height, young males have greater lung function values than young females, and Whites have greater values than Blacks. Lung function increases linearly with age until the adolescent growth spurt at age $\sim 10$ yrs in females and 12 yrs in males. The pulmonary function versus height relationship shifts with age during adolescence. Thus, a single equation or the pulmonary function-height growth chart alone does not completely describe growth during the complex adolescent period. Nevertheless, race- and sex-specific growth curves of pulmonary function versus height make it easy to display and evaluate repeated measures of pulmonary function for an individual child [29].

Details of reference populations and regression equations for children and adolescents are summarised by QUANJER et al. [30]. Lung volume reference equations have been frequently derived from relatively small populations ( $<200$ children) over a $6-12-y r$ age range when growth and developmental changes are extremely rapid. Relatively few studies have taken puberty or age into account.

A comprehensive listing of published reference equations for lung volumes was published in 1983 by the ECCS [20] and updated in 1993 [8]. A set of equations was created by combining the equations in this list with the intent to use the combined equations for adults aged 18-70 yrs with a height range of $155-195 \mathrm{~cm}$ in males, and $145-180 \mathrm{~cm}$ in females.

A report on an ATS workshop on lung volume measurements [7] reviewed published reference values in infants, pre-school children, children, adolescents and adults, and gave recommendations for selecting reference values, expressing results, measuring ancillary variables and designing future studies. Most reference equations for children are derived from Caucasian populations.

Differences due to ethnicity are not well defined [33-36]. These differences may be explained, in part, by differences in trunk length relative to standing height, but there are also differences in fat-free mass, chest dimensions and strength of respiratory muscles. Until better information is available, correction factors for Black and Asian children could be the same as those recommended for adults [7]. Reference values for RV, VC and TLC are, on average, $12 \%$ lower in Blacks than in Whites [35]; this difference may be smaller in elderly persons than in young adults [36]. Reference values for absolute lung volumes for adults of Asian ethnicity are generally considered to be lower than for Whites, but the magnitude of the differences is not well defined, and the difference may be less in Asians raised on "Western" diets during childhood [37]. According to the 
TABLE 1 Outcomes of a MEDLINE search using the keywords "reference equations" and "spirometry"

\begin{tabular}{|c|c|c|c|}
\hline First author & Year & Country/area/nature of study & Journal \\
\hline KOTANIEMI & 2004 & Finland; adults & Int J Circumpolar Health 2004; 63: 129-139 \\
\hline FALASCHETTI & 2004 & $\begin{array}{l}\text { England; prediction equations from the Health } \\
\text { Survey }\end{array}$ & Eur Respir J 2004; 23: 456-463 \\
\hline Botsıs & 2003 & $\begin{array}{l}\text { Greece; neural networks for the prediction of } \\
\text { spirometric reference values in the elderly }\end{array}$ & Med Inform Internet Med 2003; 28: 299-309 \\
\hline MustaJBEgovic & 2003 & Croatia; comparison with European reference values & Croat Med J 2003; 44: 614-617 \\
\hline Perez-Padilla & 2003 & Mexico; comparison with Mexican American children & Pediatr Pulmonol 2003; 35: 177-183 \\
\hline TORRES & 2003 & Brazil; height and arm span in children & Pediatr Pulmonol 2003; 36: 202-208 \\
\hline Golshan & 2003 & Iran & Eur Respir J 2003; 22: 529-534 \\
\hline MOHAMED & 2002 & Italy & Lung 2002; 180: 149-159 \\
\hline LANGHAMMER & 2001 & Norway & Eur Respir J 2001; 18: 770-779 \\
\hline MILIVOJEVIC-POLEKSIC & 2001 & Pacific Island & Respirology 2001; 6: 247-253 \\
\hline MARION & 2001 & USA; American Indian & Chest 2001; 120: 489-495 \\
\hline KIVASTIK & 2001 & Estonia; school children & Clin Physiol 2001; 21: 490-497 \\
\hline MANZKe & 2001 & $\begin{array}{l}\text { Germany; children aged 6-16 yrs from "hospital } \\
\text { normals" }\end{array}$ & Eur J Pediatr 2001; 160: 300-306 \\
\hline Perez-Padilla & 2001 & Mexico; Mexican workers & Salud Publica Mex 2001; 43: 113-121 (Spanish) \\
\hline Pistelli & 2000 & Italy & Am J Respir Crit Care Med 2000; 161: 899-905 \\
\hline ViJaYAn & 2000 & India; South Indian children & Indian J Chest Dis Allied Sci 2000; 42: 147-156 \\
\hline BaLtopoulos & 2000 & Greece; Greek elderly & Lung 2000; 178: 201-212 \\
\hline IP & 2000 & Chinese children and adolescents in Hong Kong & Am J Respir Crit Care Med 2000; 162: 424-429 \\
\hline DEJSOMRITRUTAI & 2000 & Thailand & J Med Assoc Thai 2000; 83: 457-466 \\
\hline MARTIN & 1998 & Canada; Quebec & Rev Mal Respir 1998; 15: 781-788 (French) \\
\hline Castellsague & 1998 & ECRHS; European populations & Respir Med 1998; 92: 401-407 \\
\hline RocA & 1998 & ECRHS; validation & Eur Respir J 1998; 11: 1354-1362 \\
\hline PAN & 1997 & China; Taiwan & Chin J Physiol 1997; 40: 165-174 \\
\hline RAJKAPPOR & 1997 & India; school children & Indian J Chest Dis Allied Sci 1997; 39: 97-105 \\
\hline LUTTMANN & 1997 & Germany; 7-18-yr-old probands & Pneumologie 1997; 51: 47-54 (German) \\
\hline ChIN & 1997 & Singapore; nonsmoking adults & Respirology 1997; 2: 143-149 \\
\hline OYARZUN & 1996 & Chile & Rev Med Chil 1996; 124: 1365-1367 (Spanish) \\
\hline GUTIERREZ & 1996 & Chilean population $>5$ yrs old & Rev Med Chil 1996; 124: 1295-1306 (Spanish) \\
\hline ENRIGHT & 1996 & USA; elderly Blacks & Chest 1996; 110: 1416-1424 \\
\hline Diez-HerRanz & 1996 & $\begin{array}{l}\text { Comparison reference values recommended by } \\
\text { the pneumology Spanish and European societies }\end{array}$ & Arch Bronconeumol 1996; 32: 459-462 (Spanish) \\
\hline Louw & 1996 & South African males (normative values) & S Afr Med J 1996; 86: 814-819 \\
\hline PARMa & 1996 & Male Italians aged $7-18$ yrs & Eur J Epidemiol 1996; 12: 263-277 \\
\hline GIRI & 1996 & Bhutan & J Assoc Physicians India 1996; 44: 320-322 \\
\hline BRANDLI & 1996 & Adult Swiss population & Thorax 1996; 51: 277-283 \\
\hline SHARP & 1996 & Japanese-American males aged $71-90$ yrs & Am J Respir Crit Care Med 1996; 153: 805-811 \\
\hline QuinTERo & 1996 & Healthy Nicaraguan male workers & Am J Ind Med 1996; 29: 41-48 \\
\hline ENRIGHT & 1995 & $\begin{array}{l}\text { USA; healthy Minnesota 65-85-yr-old males and } \\
\text { females }\end{array}$ & Chest 1995; 108: 663-669 \\
\hline SiRotKovic & 1995 & Croatia; school children from Dalmatia & Monaldi Arch Chest Dis 1995; 50: 258-263 \\
\hline
\end{tabular}


TABLE 1

$$
\text { (Continued) }
$$

\begin{tabular}{llll} 
First author & Year & Country/area/nature of study & Journal \\
\hline GORE & 1995 & Healthy adult lifetime nonsmokers in Australia & Eur Respir J 1995; 8: 773-782 \\
QUANJER & 1995 & White European children and adolescents & Pediatr Pulmonol 1995; 19: 135-142 \\
DUFETEL & 1995 & Togo; Senegalese Black children and adolescents & Rev Mal Respir 1995; 12: 135-143 (French) \\
FULTON & 1995 & USA; MW in African American adolescent females & Pediatr Pulmonol 1995; 20: 225-233 \\
\hline
\end{tabular}

NHANES: National Health and Nutrition Examination Survey; ECRHS: European Community Respiratory Health Survey; MVV: maximum voluntary ventilation

TABLE 2 Outcomes of a MEDLINE search under the keywords "reference equations" and "lung volumes"

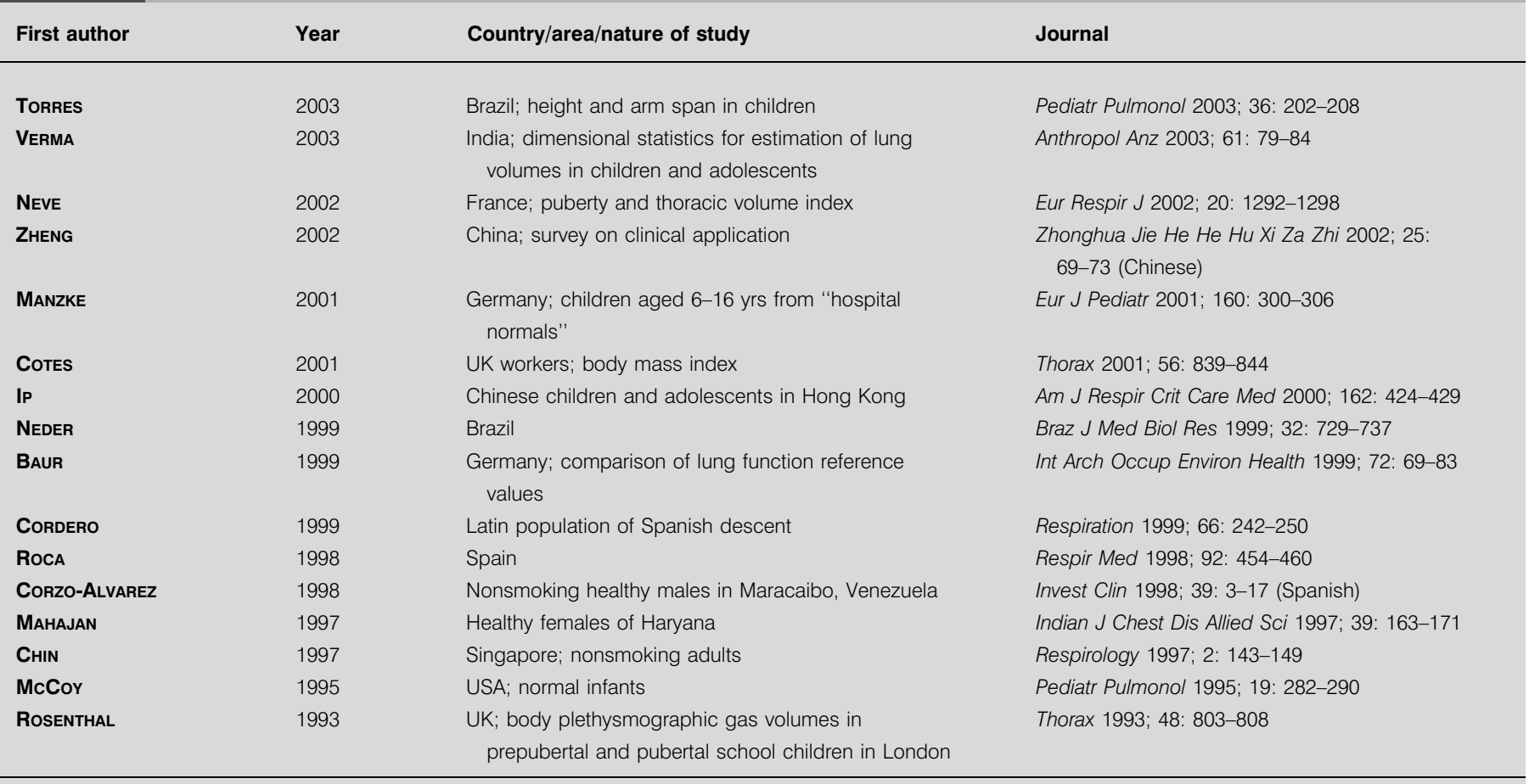

ATS 1991 document [5], no race correction is used for TLC or RV in Hispanic or Native American subjects in North America. For African American, Asian American and East Indian subjects, race corrections of 0.88 for TLC, FRC, and 0.93 for $\mathrm{RV}$, are used. Race corrections should not be used for RV/TLC.

Table 2 reports studies on reference equations published from 1993 to August 2004, and equations derived from a MEDLINE search under the keywords "reference equations" and "lung volumes". Its purpose is to recognise and encourage the continuing interest of worldwide researchers in deriving and using reference equations.

In practice, many USA and European laboratories use the reference equations for TLC, FRC and RV recommended by the 1995 ATS/ERS workshop [7] or by the ECCS [8, 20].

\section{Diffusing capacity for carbon monoxide}

Selecting reference values for $D \mathrm{~L}, \mathrm{CO}$ is more problematic than selecting reference values for spirometry because inter-laboratory differences are much larger for $D \mathrm{~L}, \mathrm{CO}[38$,
39]. Some of these differences can be attributed to the method of calculating DL,CO and adjusting for haemoglobin concentration, carboxyhaemoglobin concentration and altitude. Laboratory directors should thoughtfully select reference values that match the numbers produced in their laboratories. Optimally, it would require individual laboratories to measure $D \mathrm{~L}, \mathrm{CO}$ in a sample of healthy subjects and compare the results with several reference equations. At the very least, laboratory directors should be alert to frequent interpretations that do not match the clinical situation. Such mismatches may signal inappropriate reference values or problems with the DL,CO measurement.

Predicted values for alveolar volume $(V A)$ inspired volume $(V \mathrm{I}), \mathrm{DL}, \mathrm{CO}$ and transfer coefficient of the lung for carbon monoxide $(\mathrm{KCO})$ should be derived from the same source. As $D$ L,CO and KCO may be variably affected by factors previously described in this series of Task Force reports [4], a statement should be included describing which parameters might have been used to adjust the predicted values (e.g. VA, haemoglobin and carboxyhaemoglobin concentrations, and altitude). 
Table 3 shows studies on reference equations, published from 1995 to August 2004, and some derived from a MEDLINE search under the keywords "reference equations" and "diffusing capacity" or "diffusion". Its purpose is to recognise and encourage the continuing interest of worldwide researchers in deriving and using reference equations.

A single "summary" prediction equation was proposed by the ERS [38] and suggested by the ATS [39]. At present, however, a single equation set for $\mathrm{DL}, \mathrm{CO}$ cannot be recommended because of the relatively high inter-laboratory variability. Commonly used equations appear to be those from the 1993 ERS document [38] and those of CRAPO and MORRIS [40]. In Europe, equations from COTES et al. [41], PAOLETTI et al. [42], and RocA et al. [43] are also used.

Table 4 provides a summary of the reference values used for general issues, spirometry, lung volumes and diffusing capacity.

\section{TYPES OF VENTILATORY DEFECTS \\ General issues}

PFT interpretations should be clear, concise and informative. A mere statement of which values are normal or low is not helpful. Ideally, the principles of clinical decision making should be applied to the interpretation of the results of PFTs [44], where the post-test probability of disease is estimated after taking into consideration the pre-test probability of disease, the quality of the test results, the downside of a false-positive and false-negative interpretation, and, finally, the test results themselves and how they compare with reference values. This is often not possible because many, if not most, tests are interpreted in the absence of any clinical information. To improve this situation, it may be useful, whenever possible, to ask the physicians who are responsible for ordering tests to state the clinical question to be answered and, before testing, ask patients why they were sent for testing. Similarly, recording respiratory symptoms, such as cough, phlegm, wheezing and dyspnoea, as well as smoking status, and recent bronchodilator use could be helpful in this regard.

The interpretation will be most meaningful if the interpreter can address relevant clinical diagnoses, the chest radiograph appearance, the most recent haemoglobin value, and any suspicion of neuromuscular disease or upper airway obstruction (UAO).

\section{Obstructive abnormalities}

An obstructive ventilatory defect is a disproportionate reduction of maximal airflow from the lung in relation to the maximal volume (i.e. VC) that can be displaced from the lung [45-47]. It implies airway narrowing during exhalation and is defined by a reduced FEV1/VC ratio below the 5th percentile of the predicted value. A typical example is shown in figure 1a.

The earliest change associated with airflow obstruction in small airways is thought to be a slowing in the terminal portion of the spirogram, even when the initial part of the spirogram is barely affected [45-47]. This slowing of expiratory flow is most obviously reflected in a concave shape on the flow-volume curve. Quantitatively, it is reflected in a proportionally greater reduction in the instantaneous flow measured after $75 \%$ of the FVC has been exhaled (FEF75\%) or in mean expiratory flow between $25 \%$ and $75 \%$ of FVC than in FEV1. However, abnormalities in these mid-range flow measurements during a forced exhalation are not specific for small airway disease in individual patients [48]

As airway disease becomes more advanced and/or more central airways become involved, timed segments of the spirogram such as the FEV1 will, in general, be reduced out of proportion to the reduction in $\mathrm{VC}$.

TABLE 3 Outcome of a MEDLINE search under the keywords "reference equations" and "diffusing capacity" or "diffusion"

\begin{tabular}{|c|c|c|c|}
\hline First author & Year & Country/area/nature of study & Journal \\
\hline NeVE & 2002 & France; puberty and thoracic volume index & Eur Respir J 2002; 20: 1292-1298 \\
\hline ZHENG & 2002 & China; survey on clinical application & $\begin{array}{l}\text { Zhonghua Jie He He Hu Xi Za Zhi 2002; 25: 69-73 } \\
\text { (Chinese) }\end{array}$ \\
\hline ZANEN & 2001 & $\begin{array}{l}\text { The Netherlands; alveolar membrane diffusion capacity and } \\
\text { pulmonary capillary blood volume }\end{array}$ & Eur Respir J 2001; 18: 764-769 \\
\hline Cotes & 2001 & UK workers; body mass index & Thorax 2001; 56: 839-844 \\
\hline Hughes & 2001 & UK; in defence of $K C O(T L / V A)$ & Eur Respir J 2001; 17: 168-174 \\
\hline JOHNSON & 2000 & USA; correction for VA for both $D \mathrm{~L}, \mathrm{CO}$ and $K \mathrm{CO}$ & Respir Med 2000; 94: 28-37 \\
\hline Neder & 1999 & Brazil & Braz J Med Biol Res 1999; 32: 729-737 \\
\hline BAUR & 1999 & Germany; comparison of lung function reference values & Int Arch Occup Environ Health 1999; 72: 69-83 \\
\hline MARTIN & 1998 & Canada/Québec & Rev Mal Respir 1998; 15: 781-788 (French) \\
\hline MAHAJAN & 1997 & India; healthy females of Haryana & Indian J Chest Dis Allied Sci 1997; 39: 163-171 \\
\hline CHIN & 1997 & Singapore; nonsmoking adults & Respirology 1997; 2: 143-149 \\
\hline GUENARD & 1996 & France; elderly subjects & Eur Respir J 1996; 9: 2573-2577 \\
\hline Collard & 1996 & Belgium; obstructive sleep apnoea and obesity & Chest 1996; 110: 1189-1193 \\
\hline Chinn & 1996 & UK workers; standardised for alveolar volume & Eur Respir J 1996; 9: 1269-1277 \\
\hline Stam & 1996 & The Netherlands; at reduced alveolar volumes in children & Pediatr Pulmonol 1996; 21: 84-89 \\
\hline
\end{tabular}

KCO: transfer coefficient of the lung for carbon monoxide; $T L$ : transfer factor of the lung; $V A$ : alveolar volume; $D L, C O$ : carbon monoxide diffusing capacity. 


\section{TABLE 4 Summary of the usage of reference values}

\begin{tabular}{|c|c|}
\hline Item & Reference values \\
\hline \multirow[t]{6}{*}{ General } & $\begin{array}{l}\text { Predicted values should be obtained from studies of "normal" or "healthy" subjects with the same anthropometric (e.g. sex, } \\
\text { age and height) and ethnic characteristics of the patient being tested }\end{array}$ \\
\hline & Height and weight should be measured for each patient at the time of testing \\
\hline & If possible, all parameters should be taken from the same reference source \\
\hline & $\begin{array}{l}\text { When comparing selected reference equations with measurements performed on a sample of healthy subjects in a laboratory, } \\
\text { it is suggested to choose the reference equation that provides the sum of residuals (observed - predicted computed for } \\
\text { each adult subject, or log observed - log predicted for each subject in the paediatric age range) closest to zero }\end{array}$ \\
\hline & When using a set of reference equations, extrapolation beyond the size and age of the investigated subjects should be avoided \\
\hline & $\begin{array}{l}\text { For each lung function index, values below the 5th percentile of the frequency distribution of values measured in the reference } \\
\text { population are considered to be below the expected "normal range" }\end{array}$ \\
\hline \multirow[t]{3}{*}{ Spirometry } & $\begin{array}{l}\text { In the USA, ethnically appropriate NHANES III reference equations published in } 1999 \text { for those aged 8-80 yrs, and the } \\
\text { equations of WANG et al. [29] for children aged }<8 \text { yrs are recommended }\end{array}$ \\
\hline & $\begin{array}{l}\text { In Europe, the ECCS combined reference equations published in } 1993 \text { [8] are often used for 18-70-yr-old people, and those } \\
\text { from QUAN.JER et al. [30] for paediatric ages }\end{array}$ \\
\hline & Table 1 includes reference equations published from 1995 to August 2004 \\
\hline \multirow[t]{3}{*}{ Lung volumes } & No specific set of equations can be recommended \\
\hline & $\begin{array}{l}\text { In practice, many USA and European laboratories use the reference equations for TLC, FRC and RV recommended by the } \\
1995 \text { ATS/ERS workshop [7] or by the ECCS in } 1993 \text { [8] }\end{array}$ \\
\hline & Table 2 reports studies on reference equations published from 1993 to August 2004 \\
\hline \multirow[t]{3}{*}{ Diffusing capacity } & No specific set of equations is generally recommended \\
\hline & $\begin{array}{l}\text { Commonly used equations appear to be those by the ECCS in } 1993 \text { [38] and those of CRAPO and MoRRIS [40]. In Europe, } \\
\text { equations from Cotes et al. [41], PAOLETTI et al. [42] and RoCA et al. [43] are also used }\end{array}$ \\
\hline & Table 3 shows studies on reference equations published from 1995 to August 2004 \\
\hline
\end{tabular}

NHANES: National Health and Nutrition Examination Survey; ECCS: European Community for Coal and Steal; TLC: total lung capacity; FRC: functional residual capacity; RV: residual volume; ATS: American Thoracic Society; ERS: European Respiratory Society.
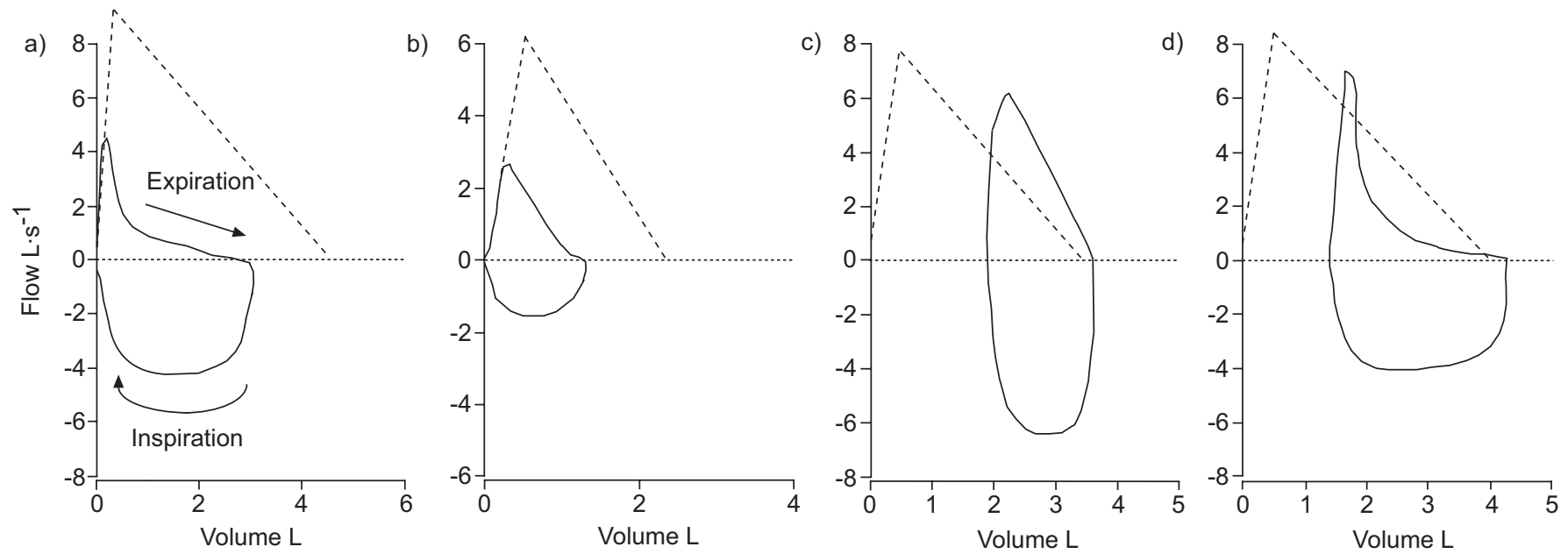

FIGURE 1. a, b) Examples of obstructive pulmonary defects with a low (a; forced expiratory volume in one second (FEV1) 38\%; FEV $1 / \mathrm{Vital}$ capacity (VC) $46 \%$; peak expiratory flow (PEF) 48\%; total lung capacity (TLC) 101\%) or normal (b; FEV1 57\%; FEV1/NC 73\%; PEF 43\%; TLC 96\%) ratio of FEV 1 NC. In both cases, TLC is normal, and flows are less than expected over the entire volume range. c) Example of a typical restrictive defect (FEV1 66\%; FEV1/NC 80\%; PEF 79\%; TLC 62\%). The TLC is low and flow is higher than expected at a given lung volume. d) Example of a typical mixed defect characterised by a low TLC and a low FEV1/NC ratio (FEV1 64\%; FEV1/NC 64\%; PEF 82\%; TLC 72\%). - - - : predicted flow-volume curves; —_: observed inspiratory and expiratory flow-volume curves (as indicated in a). 
Special attention must be paid when FEV1 and FVC are concomitantly decreased and the FEV1/FVC ratio is normal or almost normal. This pattern most frequently reflects failure of the patient to inhale or exhale completely. It may also occur when the flow is so slow that the subject cannot exhale long enough to empty the lungs to RV. In this circumstance, the flow-volume curve should appear concave toward the end of the manoeuvre. TLC will be normal and FEF75 will be low. Measurement of slow VC (inspiratory or expiratory) may then give a more correct estimate of the FEV1/VC ratio. Another possible cause of this pattern is patchy collapse of small airways early in exhalation [8,49-52]. Under these conditions, TLC may be normal, but RV is ordinarily increased. A typical example is shown in figure $1 \mathrm{~b}$. When this pattern is observed in a patient performing a maximal, sustained effort, it may be useful to repeat spirometry after treatment with an inhaled bronchodilator. Significant improvement in the FEV1, FVC or both would suggest the presence of reversible airflow obstruction.

Apart from this unusual circumstance, measurement of lung volumes is not mandatory to identify an obstructive defect. It may, however, help to disclose underlying disease and its functional consequences. For example, an increase in TLC, RV or the RV/TLC ratio above the upper limits of natural variability may suggest the presence of emphysema, bronchial asthma or other obstructive diseases [47], as well as the degree of lung hyperinflation.

Airflow resistance is rarely used to identify airflow obstruction in clinical practice. It is more sensitive for detecting narrowing of extrathoracic or large central intrathoracic airways than of more peripheral intrathoracic airways [47]. It may be useful in patients who are unable to perform a maximal forced expiratory manoeuvre.

\section{Restrictive abnormalities}

A restrictive ventilatory defect is characterised by a reduction in TLC below the 5 th percentile of the predicted value, and a normal FEV1/VC. A typical example is shown in figure 1c. The presence of a restrictive ventilatory defect may be suspected when VC is reduced, the FEV1/VC is increased ( $>85-90 \%)$ and the flow-volume curve shows a convex pattern. Once again, the pattern of a reduced $\mathrm{VC}$ and a normal or even slightly increased FEV1/VC is often caused by submaximal inspiratory or expiratory efforts and/or patchy peripheral airflow obstruction, and a reduced VC by itself does not prove a restrictive ventilatory defect. It is associated with a low TLC no more than half the time $[53,54]$.

Pneumothorax and noncommunicating bullae are special cases characterised by a normal FEV1/VC and TLC measured in a body plethysmograph, but low FEV1 and VC values. In these conditions, TLC assessed by gas dilution techniques will be low.

A low TLC from a single-breath test (such as $V$ A from the $D \mathrm{~L}, \mathrm{CO}$ test) should not be interpreted as demonstrating restriction, since such measurements systematically underestimate TLC [55]. The degree of underestimation increases as airflow obstruction worsens. In the presence of severe airflow obstruction, TLC can be underestimated by as much as $3 \mathrm{~L}$, greatly increasing the risk of misclassification of the type of
PFT abnormality $[55,56]$. A method of adjusting the singlebreath $V A$ for the effect of airway obstruction has been published, but needs further validation [57].

\section{Mixed abnormalities}

A mixed ventilatory defect is characterised by the coexistence of obstruction and restriction, and is defined physiologically when both FEV1/VC and TLC are below the 5th percentiles of their relevant predicted values. Since VC may be equally reduced in both obstruction and restriction, the presence of a restrictive component in an obstructed patient cannot be inferred from simple measurements of FEV1 and VC. A typical example is presented in figure $1 \mathrm{~d}$. If $\mathrm{FEV} 1 / \mathrm{VC}$ is low and the largest measured VC (pre- or post-bronchodilator VC or VI in the DL,CO test) is below its lower limits of normal (LLN), and there is no measurement of TLC by body plethysmography, one can state that the VC was also reduced, probably due to hyperinflation, but that a superimposed restriction of lung volumes cannot be ruled out [58]. Conversely, when FEV1/VC is low and VC is normal, a superimposed restriction of lung volumes can be ruled out $[53,54]$.

Table 5 shows a summary of the types of ventilatory defects and their diagnoses.

\section{COMMENTS ON INTERPRETATION AND PATTERNS OF DYSFUNCTION}

The definition of an obstructive pulmonary defect given in the present document is consistent with the 1991 ATS statement on interpretation [5], but contrasts with the definitions suggested by both Global Initiative for Chronic Obstructive Lung Disease (GOLD) [59] and ATS/ERS guidelines on COPD [60], in that FEV1 is referred to VC rather than just FVC and the cut-off value of this ratio is set at the 5 th percentile of the normal distribution rather than at a fixed value of 0.7 . This committee feels that the advantage of using VC in place of FVC is that the ratio of FEV1 to $\mathrm{VC}$ is capable of accurately identifying more obstructive patterns than its ratio to FVC, because FVC is more dependent on flow and volume histories [61]. In contrast with a fixed value of 0.7 , the use of the 5 th percentile does not lead to an overestimation of the ventilatory defect in older people with no history of exposure to noxious particles or gases [62].

The assumption that a decrease in major spirometric parameters, such as FEV1, VC, FEV1/VC and TLC, below their relevant 5 th percentiles is consistent with a pulmonary defect is a useful simple approach in clinical practice. Problems arise, however, when some or all of these variables lie near their upper limits of normal or LLN. In these cases, a literal interpretation of the functional pattern is too simplistic and could fail to properly describe the functional status.

The current authors suggest that additional studies should be done in these circumstances if they are indicated by the clinical problem being addressed. Such tests could include bronchodilator response, $\mathrm{DL}, \mathrm{CO}$, gas-exchange evaluation, measurement of respiratory muscle strength or exercise testing.

Caution is also recommended when TLC is at the LLN and coexists with a disease expected to lead to lung restriction. A typical example is lung resection. The expected restrictive defect would be difficult to prove on the simple basis of TLC as per cent of predicted if the latter remains above the 5th 


\begin{tabular}{|c|c|}
\hline Abnormality & Diagnosis \\
\hline \multirow[t]{5}{*}{ Obstruction } & FEV 1 NC $<5$ th percentile of predicted \\
\hline & A decrease in flow at low lung volume is not specific for small airway disease in individual patients \\
\hline & $\begin{array}{l}\text { A concomitant decrease in FEV1 and VC is most commonly caused by poor effort, but may rarely reflect airflow obstruction. } \\
\text { Confirmation of airway obstruction requires measurement of lung volumes }\end{array}$ \\
\hline & $\begin{array}{l}\text { Measurement of absolute lung volumes may assist in the diagnosis of emphysema, bronchial asthma and chronic bronchitis. It } \\
\text { may also be useful in assessing lung hyperinflation }\end{array}$ \\
\hline & Measurements of airflow resistance may be helpful in patients who are unable to perform spirometric manoeuvres \\
\hline \multirow[t]{3}{*}{ Restriction } & TLC $<5$ th percentile of predicted \\
\hline & $\begin{array}{l}\text { A reduced VC does not prove a restrictive pulmonary defect. It may be suggestive of lung restriction when } F E V_{1} / N C \text { is normal or } \\
\text { increased }\end{array}$ \\
\hline & A low TLC from a single-breath test should not be seen as evidence of restriction \\
\hline Mixed defect & FEV $1 / N C$ and $T L C<5$ th percentile of predicted \\
\hline
\end{tabular}

FEV1: forced expiratory volume in one second; VC: vital capacity; TLC: total lung capacity.

percentile of predicted as a result of subsequent lung growth or of a large TLC before surgery. Similar care must be taken in cases where diseases with opposing effects on TLC coexist, such as interstitial lung disease (ILD) and emphysema.

While patterns of physiological abnormalities can be recognised, they are seldom pathognomonic for a specific disease entity. The types of clinical illness most likely to produce an observed set of physiological disturbances can be pointed out. Regardless of the extent of testing, it is important to be conservative in suggesting a specific diagnosis for an underlying disease process based only on pulmonary function abnormalities.

The VC, FEV1, FEV1/VC ratio and TLC are the basic parameters used to properly interpret lung function (fig. 2). Although FVC is often used in place of VC, it is preferable to use the largest available $\mathrm{VC}$, whether obtained on inspiration (IVC), slow expiration (SVC) or forced expiration (i.e. FVC). The FVC is usually reduced more than IVC or SVC in airflow obstruction [61]. The FEV6 may be substituted for VC if the appropriate LLN for the FEV1/FEV6 is used (from the NHANES III equations) [12, 63]. Limiting primary interpretation of spirograms to $\mathrm{VC}, \mathrm{FEV} 1$ and FEV1/VC avoids the problem of simultaneously examining a multitude of measurements to see if any abnormalities are present, a procedure leading to an inordinate number of "abnormal" tests, even among the healthiest groups in a population [64, 65]. When the rate of abnormality for any single test is only $5 \%$, the frequency of at least one abnormal test was shown to be $10 \%$ in 251 healthy subjects when the FEV1, FVC and FEV1/FVC ratio were examined and increased to $24 \%$ when a battery of 14 different spirometric measurements were analysed [23]. It should be noted, however, that additional parameters, such as the peak expiratory flow (PEF) and maximum inspiratory flows, may assist in diagnosing extrathoracic airway obstruction.

The most important parameter for identifying an obstructive impairment in patients is the FEV1/VC ratio. In patients with respiratory diseases, a low FEV1/VC, even when FEV1 is within the normal range, predicts morbidity and mortality [66]. For healthy subjects, the meaning of a low FEV1/FVC ratio accompanied by an FEV1 within the normal range is unclear. This pattern is probably due to "dysanaptic" or unequal growth of the airways and lung parenchyma [67] (referred to in a previous ATS document as a possible physiological variant when FEV1 was $\geqslant 100 \%$ pred [5]). Whether this pattern represents airflow obstruction will depend on the prior

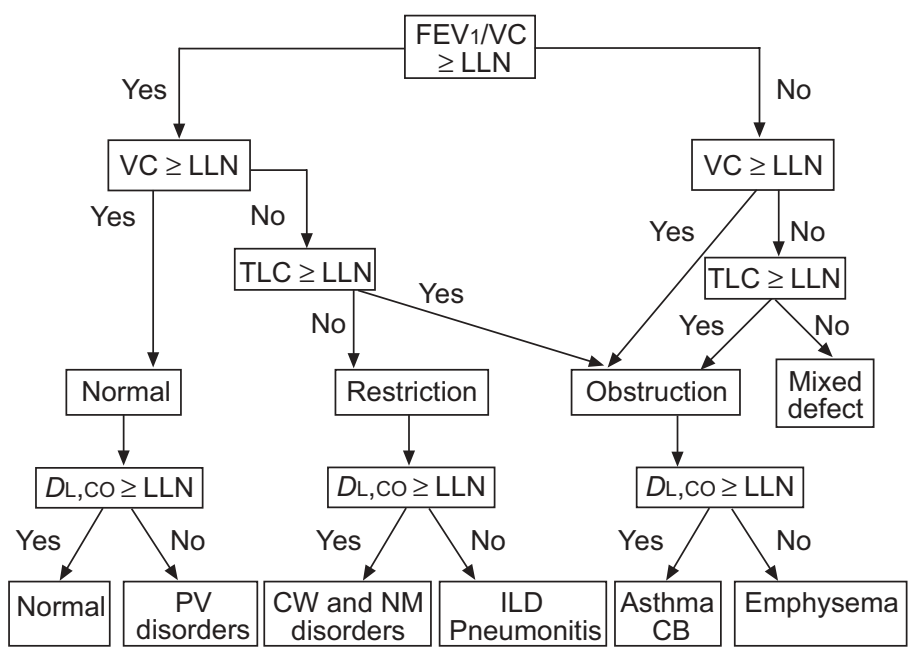

FIGURE 2. A simplified algorithm that may be used to assess lung function in clinical practice. It presents classic patterns for various pulmonary disorders. As in any such diagram, patients may or may not present with the classic patterns, depending on their illnesses, severity and lung function prior to the disease onset (e.g. did they start with a vital capacity (VC) close to the upper or lower limits of normal (LLN)). The decisions about how far to follow this diagram are clinical, and will vary depending on the questions being asked and the clinical information available at the time of testing. The forced expiratory volume in one second (FEV1)/ VC ratio and VC should be considered first. Total lung capacity (TLC) is necessary to confirm or exclude the presence of a restrictive defect when VC is below the LLN. The algorithm also includes diffusing capacity for carbon monoxide $(D\llcorner, C O)$ measurement with the predicted value adjusted for haemoglobin. In the mixed defect group, the $D\llcorner, C O$ patterns are the same as those for restriction and obstruction. This flow chart is not suitable for assessing the severity of upper airway obstruction. PV: pulmonary vascular; CW: chest wall; NM: neuromuscular; ILD: interstitial lung diseases; CB: chronic bronchitis. 
probability of obstructive disease and possibly on the results of additional tests, such as bronchodilator response, $D \mathrm{~L}, \mathrm{CO}$, gasexchange evaluation, and measurement of muscle strength or exercise testing. Expiratory flow measurements other than the FEV1 and FEV1/VC should be considered only after determining the presence and clinical severity of obstructive impairment using the basic values mentioned previously. When the FEV1 and FEV1/VC are within the expected range, the clinical significance of abnormalities in flow occurring late in the maximal expiratory flow-volume curve is limited. In the presence of a borderline value of $\mathrm{FEV} 1 / \mathrm{VC}$, however, these tests may suggest the presence of airway obstruction. The same is true for average flows, such as mid-expiratory flow (MEF25$75 \%)$, especially in children with cystic fibrosis [68, 69]. Even with this limited use, the wide variability of these tests in healthy subjects must be taken into account in their interpretation.

The maximal voluntary ventilation (MVV) is not generally included in the set of lung function parameters necessary for diagnosis or follow-up of the pulmonary abnormalities because of its good correlation with FEV1 [70]. However, it may be of some help in clinical practice. For example, a disproportionate decrease in MVV relative to FEV1 has been reported in neuromuscular disorders [71, 72] and UAO [73]. In addition, it is also used in estimating breathing reserve during maximal exercise [74], although its application may be of limited value in mild-to-moderate COPD [75, 76]. For these purposes, the current authors suggest that MVV should be measured rather than estimated by multiplying FEV1 by a constant value, as is often done in practice.

\section{SEVERITY CLASSIFICATION}

A method of categorising the severity of lung function impairment based on the FEV1 \% pred is given in table 6. It is similar to several previous documents, including GOLD [59], ATS 1986 [77], ATS 1991 [5], and the American Medical Association (AMA) [78]. The number of categories and the exact cut-off points are arbitrary.

Severity scores are most appropriately derived from studies that relate pulmonary function test values to independent indices of performance, such as ability to work and function in daily life, morbidity and prognosis [79-82]. In general, the ability to work and function in daily life is related to pulmonary function, and pulmonary function is used to rate impairment in several published systems [77-79, 83]. Pulmonary function level is also associated with morbidity,

TABLE 6 Severity of any spirometric abnormality based on the forced expiratory volume in one second (FEV1)

Degree of severity

\begin{tabular}{lc}
\hline Mild & $>70$ \\
Moderate & $60-69$ \\
Moderately severe & $50-59$ \\
Severe & $35-49$ \\
Very severe & $<35$ \\
\hline
\end{tabular}

$\%$ pred: \% predicted. and the patients with lower function have more respiratory complaints [82].

Lung function level is also associated with prognosis, including a fatal outcome from heart as well as lung disease [84, 85], even in patients who have never smoked [86]. In the Framingham study, VC was a major independent predictor of cardiovascular morbidity and mortality [84, 85]. In several occupational cohorts, FEV1 and FEV1/FVC were independent predictors of all-cause or respiratory disease mortality [87-89]. In addition, a meta-analysis of mortality in six surveys in various UK working populations showed that the risk of dying from COPD was related to the FEV1 level. In comparison to those whose FEV1 at an initial examination was within 1 SD of average, those whose FEV1 was $>2$ SD below average were 12 times more likely to die of COPD, more than 10 times as likely to die of non-neoplastic respiratory disease, and more than twice as likely to die of vascular disease over a 20-yr follow-up period [90]. Although there is good evidence that FEV1 correlates with the severity of symptoms and prognosis in many circumstances $[79,82,90]$, the correlations do not allow one to accurately predict symptoms or prognosis for individual patients.

The DL,CO is also an important predictor of mortality both in the general population [91] and in patients after pulmonary resection [92].

Though the FEV1 \% pred is generally used to grade severity in patients with obstructive, restrictive and mixed pulmonary defects, it has little applicability to patients with UAO, such as tracheal stenosis, where obstruction could be life-threatening and yet be classified as mildly reduced by this scheme. In addition, there is little data documenting the performance of other functional indexes, such as FRC in airflow obstruction or TLC in lung restriction as indices to categorise severity of impairment.

$\mathrm{VC}$ is reduced in relation to the extent of loss of functioning lung parenchyma in many nonobstructive lung disorders. It is also of some use in assessing respiratory muscle involvement in certain neuromuscular diseases. VC may be only slightly impaired in diffuse interstitial diseases of sufficient severity to lead to marked loss of diffusing capacity and severe blood gas abnormalities [63]. The onset of a severe respiratory problem in patients with a rapidly progressive neuromuscular disease may be associated with only a small decrement in VC $[47,93]$.

FEV1 and FVC may sometimes fail to properly identify the severity of ventilatory defects, especially at the very severe stage for multiple reasons. Among them are the volume history effects of the deep breath preceding the forced expiratory manoeuvre on the bronchial tone and, thus, calibre [94-98], and the inability of these parameters to detect whether tidal breathing is flow limited or not [99-102]. The FEV1/VC ratio should not be used to determine the severity of an obstructive disorder, until new research data are available. Both the FEV1 and $\mathrm{VC}$ may decline with the progression of disease, and an FEV1/VC of $0.5 / 1.0$ indicates more impairment than one of $2.0 / 4.0$, although the ratio of both is $50 \%$. While the FEV1/VC ratio should not routinely be used to determine the severity of an obstructive disorder, it may be of value when persons having genetically large lungs develop obstructive disease. In 
these cases, the FEV1/VC ratio may be very low (60\%), when the FEV1 alone is within the mild category of obstruction (i.e. $>70 \%$ pred).

Recent studies have stressed the importance of additional measurements in assessing the severity of the disease. For example, when airflow obstruction becomes severe, FRC, RV, TLC and RV/TLC tend to increase as a result of decreased lung elastic recoil and/or dynamic mechanisms [47, 103, 104]. The degree of hyperinflation parallels the severity of airway obstruction [58]. On one hand, lung hyperinflation is of benefit because it modulates airflow obstruction, but, on the other hand, it causes dyspnoea because of the increased elastic load on inspiratory muscles [47]. In a recent investigation, resting lung hyperinflation, measured as inspiratory capacity (IC)/ TLC, was an independent predictor of respiratory and allcause mortality in COPD patients [105]. In addition, in either severe obstructive or restrictive diseases, tidal expiratory flow often impinges on maximum flow $[98,99,102]$. This condition, denoted as expiratory flow limitation during tidal breathing (EFL), is relatively easy to measure in practice by comparing tidal and forced expiratory flow-volume loops. Its clinical importance is that it contributes to increased dyspnoea [100], puts the inspiratory muscles at a mechanical disadvantage [43] and causes cardiovascular side-effects [106]. Although there currently isn't sufficient evidence to recommend the routine use of measurements of hyperinflation or EFL to score the severity of lung function impairment, they may be helpful in patients with disproportionate differences between spirometric impairment and dyspnoea.

Finally, the reported increase in RV in obstruction is deemed to be a marker of airway closure [47, 103]. Although its clinical relevance remains uncertain, especially with regard to assessment of severity, RV may be useful in special conditions, including predicting the likelihood of lung function improvement after lung volume-reduction surgery [104].

Table 7 shows the summary of the considerations for severity classification.

\section{BRONCHODILATOR RESPONSE}

Bronchial responsiveness to bronchodilator medications is an integrated physiological response involving airway epithelium, nerves, mediators and bronchial smooth muscle. Since

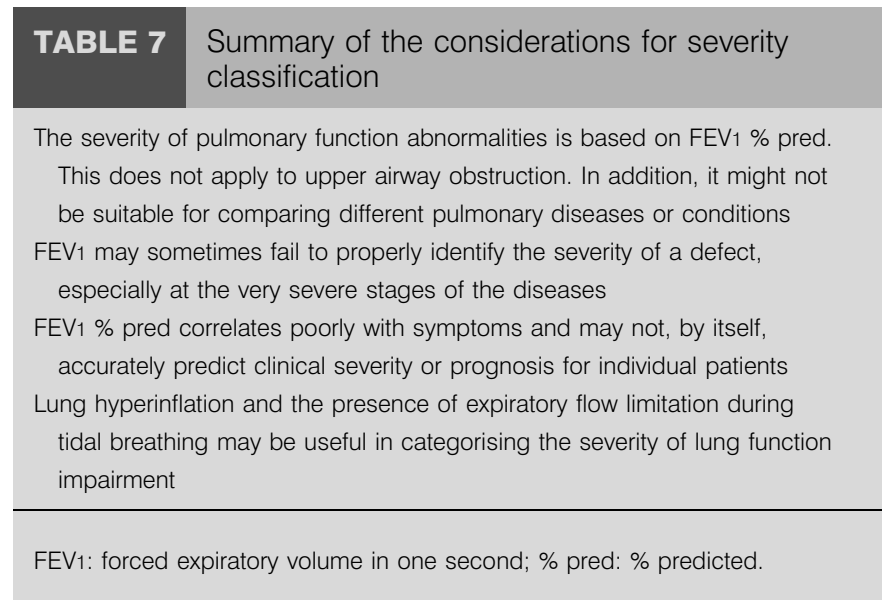

the within-individual difference in response to a bronchodilator is variable, the assumption that a single test of bronchodilator response is adequate to assess both the underlying airway responsiveness and the potential for therapeutic benefits of bronchodilator therapy is overly simplistic [107]. Therefore, the current authors feel that the response to a bronchodilator agent can be tested either after a single dose of a bronchodilator agent in the PFT laboratory or after a clinical trial conducted over 2-8 weeks.

The correlation between bronchoconstriction and bronchodilator response is imperfect, and it is not possible to infer with certainty the presence of one from the other.

There is no consensus about the drug, dose or mode of administering a bronchodilator in the laboratory. However, when a metered dose inhaler is used, the following procedures are suggested in order to minimise differences within and between laboratories. Short-acting $\beta_{2}$-agonists, such as salbutamol, are recommended. Four separate doses of $100 \mu \mathrm{g}$ should be used when given by metered dose inhaler using a spacer. Tests should be repeated after a 15-min delay. If a bronchodilator test is performed to assess the potential therapeutic benefits of a specific drug, it should be administered in the same dose and by the same route as used in clinical practice, and the delay between administration and repeated spirometric measurements should reflect the reported time of onset for that drug.

The first step in interpreting any bronchodilator test is to determine if any change greater than random variation has occurred. The per cent change in FVC and FEV1 after bronchodilator administration in general population studies [108-110] and patient populations [101, 111-113] are summarised in table 8 . Studies show a tendency for the calculated bronchodilator response to increase with decreasing baseline VC or FEV1, regardless of whether the response was considered as an absolute change or as a per cent of the initial value. Bronchodilator responses in patient-based studies are, therefore somewhat higher than those in general population studies.

There is no clear consensus about what constitutes reversibility in subjects with airflow obstruction [111, 114]. In part, this is because there is no consensus on how a bronchodilator response should be expressed, the variables to be used, and, finally, the kind, dose and inhalation mode of bronchodilator agent. The three most common methods of expressing bronchodilator response are per cent of the initial spirometric value, per cent of the predicted value, and absolute change.

Expressing the change in FEV1 and/or FVC as a per cent of predicted values has been reported to have advantages over per cent change from baseline [115]. When using per cent change from baseline as the criterion, most authorities require a $12-15 \%$ increase in FEV1 and/or FVC as necessary to define a meaningful response. Increments of $<8 \%$ (or $<150 \mathrm{~mL}$ ) are likely to be within measurement variability $[107,115]$. The current authors recommend using the per cent change from baseline and absolute changes in FEV1 and/or FVC in an individual subject to identify a positive bronchodilator response. Values $>12 \%$ and $200 \mathrm{~mL}$ compared with baseline during a single testing session suggest a "significant" bronchodilatation. If the change in FEV1 is not significant, a 


\section{TABLE 8 Selected studies of bronchodilator response}

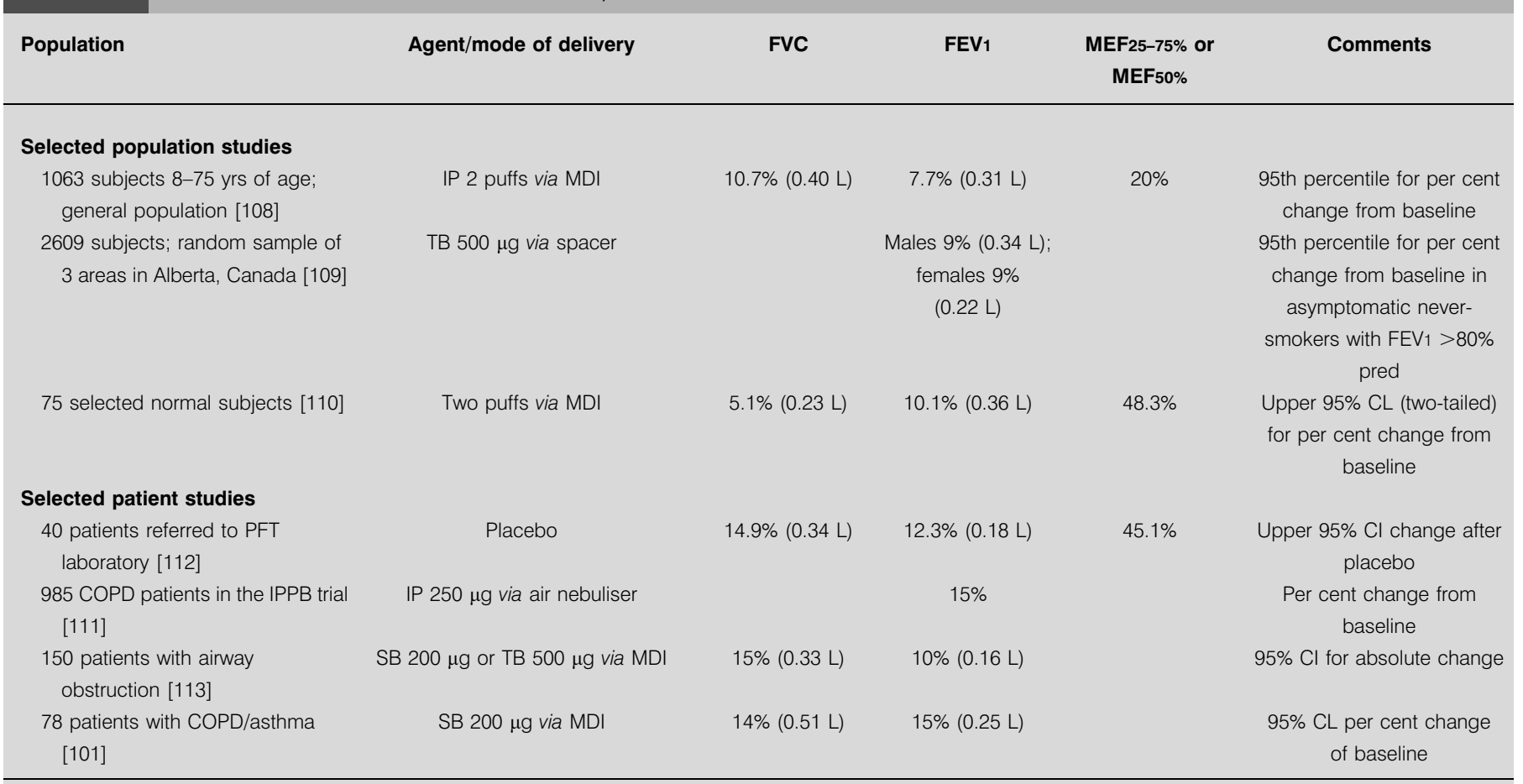

FVC: forced vital capacity; FEV1: forced expiratory volume in one second; MEF25-75\%: mean flow between $25 \%$ and $75 \%$ of FVC; MEF50\%: flow at $50 \%$ of FVC; IP: isoproterenol; MDI: metered dose inhaler; TB: terbutaline; \% pred: \% predicted; SB: salbutamol; CL: confidence limits; PFT:pulmonary function tests; Cl: confidence interval; COPD: chronic obstructive pulmonary disease; IPPB: intermittent positive pressure breathing; Other variables as in table 6.

decrease in lung hyperinflation may indicate a significant response [101]. The lack of a response to bronchodilator testing in a laboratory does not preclude a clinical response to bronchodilator therapy.

The MEF25-75\% is a highly variable spirometric test, in part because it depends on FVC, which increases with expiratory time in obstructed subjects. If FVC changes, post-bronchodilator MEF $25-75 \%$ is not comparable with that measured before the bronchodilator. Volume adjustment of MEF25-75\% has been proposed to solve this problem [116, 117]. At least two studies have assessed the utility of MEF25-75\%. The results were disappointing; only $8 \%$ of asthmatics [117] and $7 \%$ of patients with COPD were identified as outside the expected range by MEF25-75\% criteria alone. Tests such as the FEV1/VC ratio and instantaneous flows measured at some fraction of the VC may also be misleading in assessing bronchodilator response if expiratory time changes are not considered and if flows are not measured at the same volume below TLC.

If the change is above the threshold of natural variability, then the next step is to determine if this change is clinically important. This aspect of the interpretation is harder to define and depends on the reasons for undertaking the test. For instance, even if asthmatics tend to show a larger increase in flow and volume after inhaling a dilator agent than COPD patients, the response to a bronchodilator has never been shown to be capable of clearly separating the two classes of patients [101, 109, 111, 114]. In addition, it must be also acknowledged that responses well below the significant thresholds may be associated with symptom improvement and patient performance [118]. The possible reasons are discussed as follows.

Quite often, responses to bronchodilator therapy are unpredictably underestimated by FEV1 and/or FVC in comparison to airway resistance or flow measured during forced expiratory manoeuvres initiated from a volume below TLC (partial expiratory flow-volume manoeuvres) in both healthy subjects and patients with chronic airflow obstruction [8, 101, 102, 119122]. These findings are probably due to the fact that deep inhalations tend to reduce airway calibre, especially after a bronchodilator [101, 120]. In patients with airflow obstruction, the increase in expiratory flow after bronchodilation is often associated with a decrease in FRC or an increase in IC of similar extent at rest and during exercise [101, 123]. The improvement of the lung function parameters in the tidal breathing range and not following a deep breath may explain the decrease in shortness of breath after inhaling a bronchodilator, despite no or minimal changes in FEV1 and/or FVC. Short-term intra-individual variabilities for partial flows and IC have been reported [101]. Therefore, the lack of increase of FEV1 and/or FVC after a bronchodilator is not a good reason to avoid 1-8-week clinical trial with bronchoactive medication.

An isolated increase in FVC $(>12 \%$ of control and $>200 \mathrm{~mL})$ not due to increased expiratory time after salbutamol is a sign of 


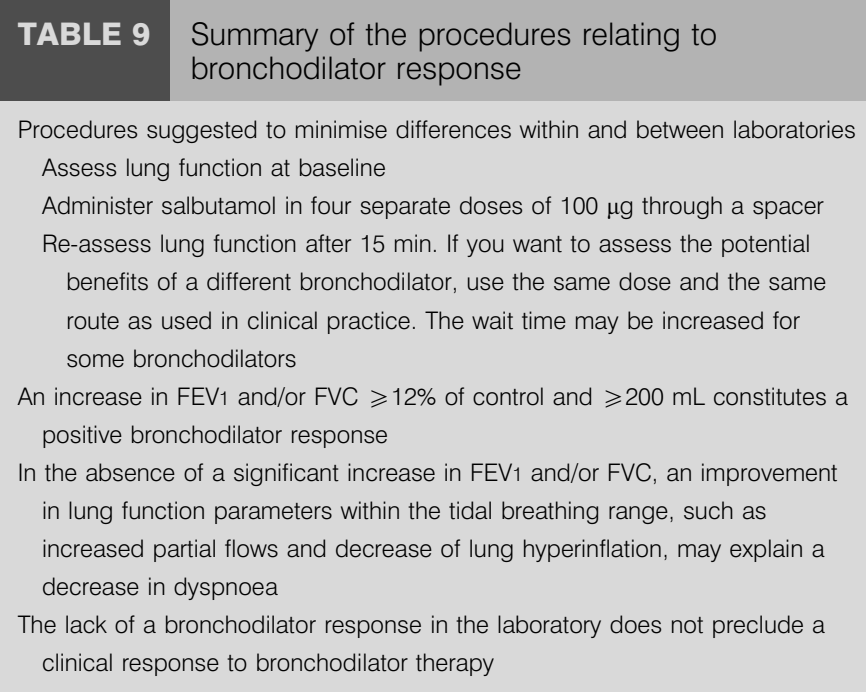

FEV1: forced expiratory volume in one second; FVC: forced vital capacity

bronchodilation [124]. This may, in part, be related to the fact that deep inhalations tend to reduce airway calibre and/or airway wall stiffness, especially after a bronchodilator [101, 120].

Table 9 shows a summary of the suggested procedures for laboratories relating to bronchodilator response.

\section{CENTRAL AND UPPER AIRWAY OBSTRUCTION}

Central airway obstruction and UAO may occur in the extrathoracic (pharynx, larynx, and extrathoracic portion of the trachea) and intrathoracic airways (intrathoracic trachea and main bronchi). This condition does not usually lead to a decrease in FEV1 and/or VC, but PEF can be severely affected. Therefore, an increased ratio of FEV1 divided by PEF $\left(\mathrm{mL} \cdot \mathrm{L}^{-1} \cdot \mathrm{min}^{-1}\right)$ can alert the clinician to the need for an inspiratory and expiratory flow-volume loop [125]. A value $>8$ suggests central or upper airway obstruction may be present [126]. Poor initial effort can also affect this ratio.

At least three maximal and repeatable forced inspiratory and forced expiratory flow-volume curves are necessary to evaluate for central or upper airway obstruction. It is critical that the patient's inspiratory and expiratory efforts are near maximal and the technician should confirm this in the quality notes. When patient effort is good, the pattern of a repeatable plateau of forced inspiratory flow, with or without a forced expiratory plateau, suggests a variable extrathoracic central or upper airway obstruction (fig. 3). Conversely, the pattern of a repeatable plateau of forced expiratory flow, along with the lack of a forced inspiratory plateau suggests a variable, intrathoracic central or upper airway obstruction. The pattern of a repeatable plateau at a similar flow in both forced inspiratory and expiratory flows suggests a fixed central or upper airway obstruction (fig. 3).

In general, maximum inspiratory flow is largely decreased with an extrathoracic airway obstruction, because the pressure surrounding the airways (which is almost equal to atmospheric) cannot oppose the negative intraluminal pressure generated with the inspiratory effort. In contrast, it is little affected by an intrathoracic airway obstruction, for the pressure surrounding the intrathoracic airways (which is close to pleural pressure) strongly opposes the negative intraluminal pressure on inspiration, thus limiting the effects of the obstruction on flow. With unilateral main bronchus obstruction, a rare event, maximum inspiratory flow tends to be higher at the beginning than towards the end of the forced inspiration because of a delay in gas filling (fig. 4).

Maximum expiratory flow at high lung volume (especially peak flow) is generally decreased in both intrathoracic and extrathoracic lesions [126-129]. In contrast, maximum flows may be normal in the presence of a variable lesion, such as vocal cord paralysis. Flow oscillations (saw-tooth pattern) may be occasionally observed on the either inspiratory or expiratory phase, and probably represent a mechanical instability of the airway wall.

The effects of anatomical or functional lesions on maximum flows depend on the site of the obstruction, kind of lesion (variable or fixed) and the extent of anatomical obstruction [61, 127, 130]. Typical cases of extra- and intrathoracic central or upper airway obstruction are reported in figures 3 and 4 . The absence of classic spirometric patterns for central airway

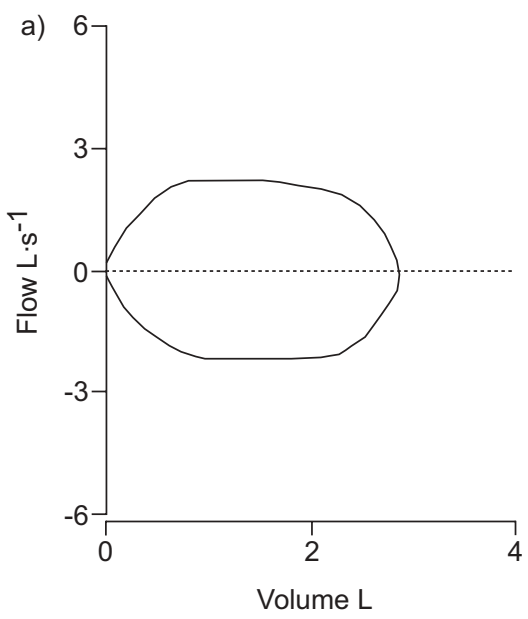

b)

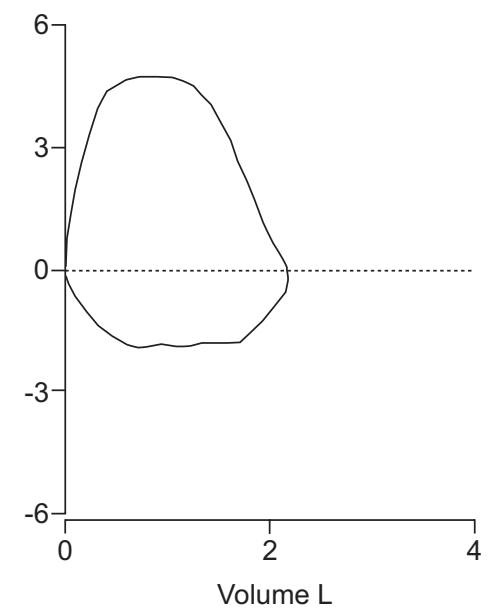

c)

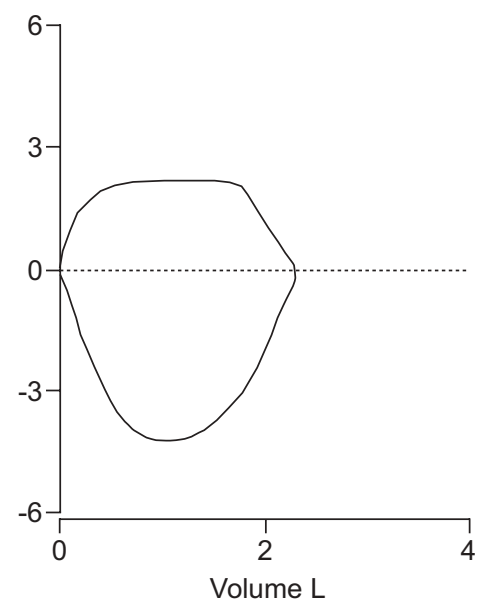

FIGURE 3. Idealised examples of a) fixed, b) variable extrathoracic, and c) variable intrathoracic airway obstruction. 


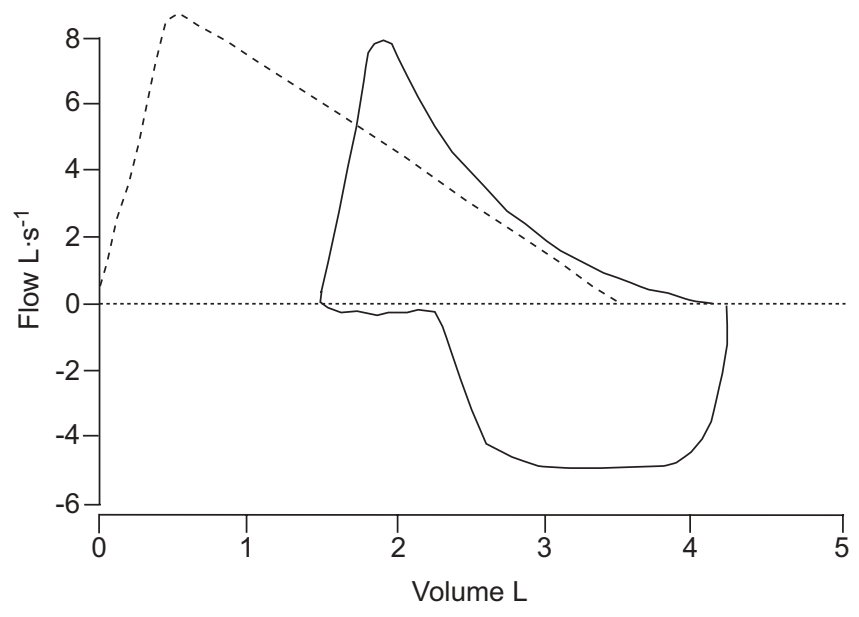

FIGURE 4. Example of unilateral main bronchus obstruction due to a valve-like mechanism occluding the main left stem bronchus during inspiration as a result of a surgical scar. There is a delay in gas filling towards the end of the forced inspiration as evidence of the variable unilateral main bronchus obstruction (forced expiratory volume in one second (FEV1): 76\%; FEV1/vital capacity: $70 \%$; peak expiratory flow: 93\%; total lung capacity: $80 \%$ ). -----: predicted expiratory flow-volume loop; recorded maximum inspiratory and expiratory flow-volume loops.

obstruction does not accurately predict the absence of pathology. As a result, clinicians need to maintain a high degree of suspicion for this problem, and refer suspected cases for visual inspection of the airways. The authors feel that, although maximum inspiratory and expiratory flow-volume loops are of great help to alert clinicians to the possibility of central or upper airway obstruction, endoscopic and radiological techniques are the next step to confirm the dysfunction.

The parameters presented in table 10 may help to distinguish intrathoracic from extrathoracic airway obstructions.

Table 11 gives a summary of the relevant issues concerning UAO.

\section{INTERPRETATION OF CHANGE IN LUNG FUNCTION}

Evaluation of an individual's change in lung function following an intervention or over time is often more clinically valuable than a single comparison with external reference (predicted) values. It is not easy to determine whether a measured change reflects a true change in pulmonary status or

\begin{tabular}{|c|c|c|c|}
\hline \multirow[t]{3}{*}{ TABLE 10} & \multicolumn{3}{|c|}{$\begin{array}{l}\text { Lung function parameters capable of } \\
\text { differentiating extrathoracic from intrathoracic } \\
\text { obstruction }\end{array}$} \\
\hline & \multicolumn{2}{|c|}{ Extrathoracic obstruction } & \multirow{2}{*}{$\begin{array}{l}\text { Intrathoracic } \\
\text { obstruction }\end{array}$} \\
\hline & Fixed & Variable & \\
\hline PEF & Decreased & Normal or decreased & Decreased \\
\hline MIF50 & Decreased & Decreased & Normal or decreased \\
\hline MIF50/MEF50 & $\sim 1$ & $<1$ & $>1$ \\
\hline
\end{tabular}

PEF: peak expiratory flow; MIF50: maximum inspiratory flow at $50 \%$ of forced vital capacity (FVC); MEF50: maximum expiratory flow at $50 \%$ of FVC.

\section{TABLE 11 Summary of the issues concerning central or upper airway obstruction}

Special attention should be paid by the technicians to obtain maximal and repeatable PEFs and forced inspiratory manoeuvres if there is a clinical or spirometric reason to suspect upper airway obstruction

Be aware of how to distinguish intrathoracic from extrathoracic airway obstruction (table 10)

Confirm the presence of central and upper airway obstruction with imaging and/or endoscopic techniques

PEF: peak expiratory flow.

is only a result of test variability. All lung function measurements tend to be more variable when made weeks to months apart than when repeated at the same test session or even daily $[25,131]$. The short-term repeatability of tracked parameters should be measured using biological controls. This is especially important for the $D \mathrm{~L}, \mathrm{CO}[132,133]$, since small errors in measurements of inspiratory flows or exhaled gas concentrations translate into large $D \mathrm{~L}, \mathrm{CO}$ errors. The variability of lung volume measurements has recently been reviewed [134].

The optimal method of expressing the short-term variability (measurement noise) is to calculate the coefficient of repeatability (CR) instead of the more popular coefficient of variation [135]. Change measured for an individual patient that falls outside the $\mathrm{CR}$ for a given parameter may be considered significant. The CR may be expressed as an absolute value (such as $0.33 \mathrm{~L}$ for FEV1 or 5 units for $\mathrm{DL}, \mathrm{CO}$ ) [136] or as a percentage of the mean value (such as $11 \%$ for FEV1) [137].

It is more likely that a real change has occurred when more than two measurements are performed over time. As shown in table 12, significant changes, whether statistical or biological,

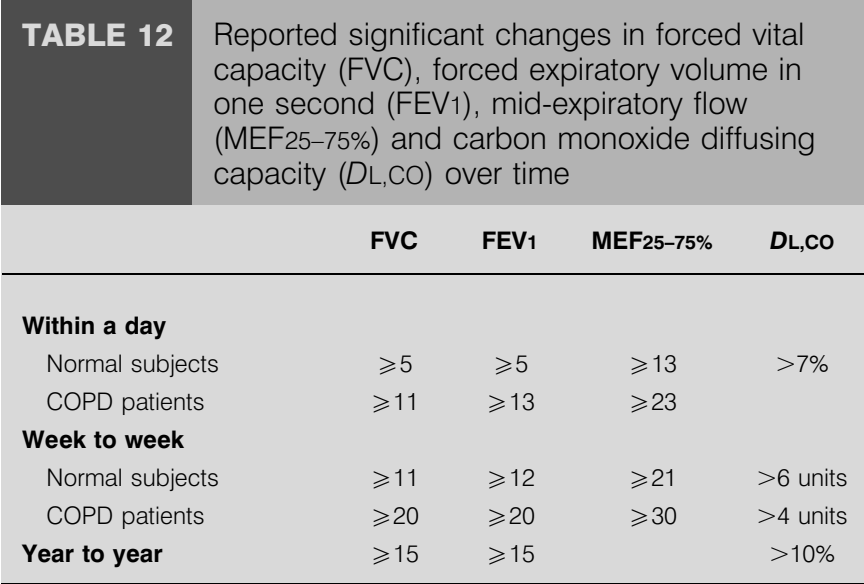

The variables are the same as in tables 6 and 8 . Results for spirometry are rounded to the nearest integer $[25,128]$. The within-day $D L, C 0$ variability is from a study of diurnal variation in healthy nonsmokers [133]. The week-to-week coefficient of repeatability $(\mathrm{CR})$ is given for $\mathrm{DL}, \mathrm{CO}$ in units of $\mathrm{mL} \cdot \mathrm{min}^{-1} \cdot \mathrm{mmHg}^{-1}$, as calculated from CRs originally stated in units of $\mathrm{mmol} \cdot \mathrm{min}^{-1} \cdot \mathrm{kPa}^{-1}$ [138]. The year-to-year variability of healthy adults is given using a $95 \%$ confidence interval [139]. CRs from repeatability testing performed in your own laboratory should be substituted for the values in this table. COPD: chronic obstructive pulmonary disease. 
vary by parameter, time period and the type of patient. When there are only two tests available to evaluate change, the large variability necessitates relatively large changes to be confident that a significant change has in fact occurred. Thus, in subjects with relatively "normal" lung function, year-to-year changes in FEV1 over 1 yr should exceed $15 \%$ before confidence can be given to the opinion that a clinically meaningful change has occurred [5].

For tracking change, FEV1 has the advantage of being the most repeatable lung function parameter and one that measures changes in both obstructive and restrictive types of lung disease. Two-point, short-term changes of $>12 \%$ and $>0.2 \mathrm{~L}$ in the FEV1 are usually statistically significant and may be clinically important. Changes slightly less than these may, perhaps, be equally significant, depending on the reproducibility of the pre- and post-bronchodilator results. Other parameters such as VC, IC, TLC and DL,CO may also be tracked in patients with ILD or severe COPD [138, 140-142]. Tests like VC and FVC may be relevant to COPD because they may increase when FEV1 does not, and changes in DL,CO, in the absence of change in spirometry variables, may be clinically important. Again, when too many indices of lung function are tracked simultaneously, the risk of false-positive indications of change increases.

The clinician seeing the patient can often interpret results of serial tests in a useful manner, which is not reproducible by any simple algorithm. Depending on the clinical situation, statistically insignificant trends in lung function may be meaningful to the clinician. For example, seemingly stable test results may provide reassurance in a patient receiving therapy for a disease that is otherwise rapidly progressive. The same test may be very disappointing if one is treating a disorder that is expected to improve dramatically with the therapy prescribed. Conversely, a statistically significant change may be of no clinical importance to the patient. The largest errors occur in attempting to interpret serial changes in subjects without disease, because test variability will usually far exceed the true annual decline, and reliable rates of change for an individual subject cannot be calculated without prolonged follow-up [143].

Test variability can be reduced when lung function standards and guidelines are followed strictly. Simple plots (i.e. trending) of lung function with time can provide additional information to help differentiate true change in lung function from noise. Measuring decline in lung function as a means of identifying individuals (such as smokers) who are losing function at excessive rates has been proposed. However, establishing an accelerated rate of loss in an individual is very difficult, and requires many measurements over several years with meticulous quality control of the measurements.

Table 13 shows a summary of the considerations involved in interpreting lung function changes.

\section{DL,CO INTERPRETATION}

The lower 5 th percentile of the reference population should be used as LLN for DL,CO and KCO (if the latter is used). Table 14 presents a scheme to grade the severity of reductions in $D \mathrm{~L}, \mathrm{CO}$.

\section{TABLE 13 Summary of the considerations for the interpretation of change in lung function}

$\mathrm{Be}$ aware of possible significant changes in lung function parameters over time (table 12)

Multiple measurements over time are more likely to signal a real change in lung function than two measurements

When too many indices of lung function are tracked simultaneously, the risk of false-positive indications of change increases

Clinical interpretation of serial tests should not be based solely on the coefficient of repeatability, but also on the clinical findings

TABLE 14 Degree of severity of decrease in diffusing capacity for carbon monoxide $(D\llcorner, C O)$

\begin{tabular}{lc} 
Degree of severity & DL,Co \% pred \\
\hline Mild & $>60 \%$ and $<$ LLN \\
Moderate & $40-60 \%$ \\
Severe & $<40$
\end{tabular}

$\%$ pred: \% predicted; LLN: lower limits of normal.

The pathophysiological importance of this test has been recently reviewed [144, 145].

Interpreting the $\mathrm{DL}, \mathrm{CO}$, in conjunction with spirometry and lung volumes assessment, may assist in diagnosing the underlying disease (fig. 2). For instance, normal spirometry and lung volumes associated with decreased DL,CO may suggest anaemia, pulmonary vascular disorders, early ILD or early emphysema. In the presence of restriction, a normal DL,CO may be consistent with chest wall or neuromuscular disorders, whereas a decrease suggests ILDs. In the presence of airflow obstruction, a decreased DL,CO suggests emphysema [146], but airway obstruction and a low DL,CO are also seen in lymphangioleiomyomatosis [147]. Patients with ILD, sarcoidosis and pulmonary fibrosis usually have a low DL,CO [135137, 140]. A low DL,CO is also seen in patients with chronic pulmonary embolism, primary pulmonary hypertension [148], and other pulmonary vascular diseases. These patients may or may not also have restriction of lung volumes [149].

A high DL,CO is associated with asthma [150], obesity [151] and intrapulmonary haemorrhage [152].

Adjustments of $\mathrm{DL}, \mathrm{CO}$ for changes in haemoglobin and carboxyhaemoglobin are important, especially in situations where patients are being monitored for possible drug toxicity, and where haemoglobin is subject to large shifts (e.g. chemotherapy for cancer).

Adjusting $D \mathrm{~L}, \mathrm{CO}$ for lung volume using $D \mathrm{~L}, \mathrm{CO} / V \mathrm{~A}$ or $\mathrm{DL}, \mathrm{CO} /$ TLC is controversial $[153,154]$. Conceptually, a loss of DL,CO that is much less than a loss of volume (low DL,CO but high $D \mathrm{~L}, \mathrm{CO} / V \mathrm{~A})$ might suggest an extraparenchymal abnormality, such as a pneumonectomy or chest wall restriction, whereas a loss of DL,CO that is much greater than a loss of volume (low $D \mathrm{~L}, \mathrm{CO}$ and low $D \mathrm{~L}, \mathrm{CO} / V \mathrm{~A})$ might suggest parenchymal abnormalities. The relationship between $D \mathrm{~L}, \mathrm{CO}$ and lung 


\section{TABLE 15 Summary of the considerations for diffusing capacity for carbon monoxide $(D\llcorner, C O)$ interpretation}

Refer to a scheme to grade the severity of reductions in DL,CO (table 14) Interpreting $D \mathrm{~L}, \mathrm{CO}$ in conjunction with spirometry and lung volumes may assist in diagnosing the underlying disease (fig. 2)

Adjustments of $D \mathrm{~L}, \mathrm{CO}$ for changes in haemoglobin and carboxyhaemoglobin are important

The relationship between $D\llcorner, C O$ and lung volume is not linear, so $D\llcorner, C O / V A$ or $D L, C O / T L C$ do not provide an appropriate way to normalise $D L, C O$ for lung volume

Nonlinear adjustments may be considered, but their clinical utility must be established before they can be recommended

VA: alveolar volume; TLC: total lung capacity

volume, however, is not linear and markedly less than 1:1, so these simple ratios as traditionally reported do not provide an appropriate way to normalise DL,CO for lung volume [154159]. Nonlinear adjustments may be considered, but their clinical utility must be established before they can be recommended. Meanwhile, it is advisable to keep examining $D$ L,CO/VA and VA separately [153], in so far as it may provide information on disease pathophysiology that cannot be obtained from their product, the DL,CO.

Table 15 shows a summary on the considerations for DL,CO interpretation.

\section{ABBREVIATIONS}

Table 16 contains a list of abbreviations and their meanings, which have been used in this series of Task Force reports.

\section{TABLE 16 List of abbreviations and meanings}

\begin{tabular}{|c|c|}
\hline ATPD & Ambient temperature, ambient pressure, and dry \\
\hline ATPS & Ambient temperature and pressure saturated with water vapour \\
\hline BTPS & $\begin{array}{l}\text { Body temperature (i.e. } 37^{\circ} \mathrm{C} \text { ), ambient pressure, saturated with } \\
\text { water vapour }\end{array}$ \\
\hline C & Centigrade \\
\hline CFC & Chlorofluorocarbons \\
\hline cm & Centimetres \\
\hline $\mathrm{COHb}$ & Carboxyhaemoglobin \\
\hline$D L, C O$ & $\begin{array}{l}\text { Diffusing capacity for the lungs measured using carbon } \\
\text { monoxide, also known as transfer factor }\end{array}$ \\
\hline$D L, C O / V A$ & $\begin{array}{l}\text { Diffusing capacity for carbon monoxide per unit of alveolar } \\
\text { volume, also known as Kco }\end{array}$ \\
\hline DM & Membrane-diffusing capacity \\
\hline DT & Dwell time of flow $>90 \%$ of PEF \\
\hline EFL & Expiratory flow limitation \\
\hline ERV & Expiratory reserve volume \\
\hline EV & Back extrapolated volume \\
\hline EVC & Expiratory vital capacity \\
\hline$F A, X$ & Fraction of gas $X$ in the alveolar gas \\
\hline$F A, X, t$ & Alveolar fraction of gas $X$ at time $t$ \\
\hline FEF25-75\% & Mean forced expiratory flow between $25 \%$ and $75 \%$ of FVC \\
\hline FEFX\% & $\begin{array}{l}\text { Instantaneous forced expiratory flow when X\% of the FVC has } \\
\text { been expired }\end{array}$ \\
\hline FEV1 & Forced expiratory volume in one second \\
\hline FEVt & Forced expiratory volume in t seconds \\
\hline
\end{tabular}

\section{TABLE 16 (Continued)}

$\mathbf{F E}, \mathbf{X} \quad$ Fraction of expired gas $X$

FIFX\% Instantaneous forced inspiratory flow at the point where $\mathrm{X} \%$ of the FVC has been inspired

$\mathbf{F} \mathbf{1}, \mathbf{X} \quad$ Fraction of inspired gas $X$

FIVC Forced inspiratory vital capacity

FRC Functional residual capacity

FVC Forced vital capacity

$\mathrm{H}_{2} \mathrm{O} \quad$ Water

$\mathrm{Hb} \quad$ Haemoglobin

$\mathrm{Hg} \quad$ Mercury

Hz Hertz; cycles per second

IC Inspiratory capacity

IRV Inspiratory reserve volume

IVC Inspiratory vital capacity

Kco Transfer coefficient of the lung (i.e. DL,CO/NA)

kg Kilograms

kPa Kilopascals

L L Litres

L. min $^{-1} \quad$ Litres per minute

$\mathbf{L} \cdot \mathbf{s}^{-1} \quad$ Litres per second

lb Pounds

MEFX\% Maximal instantaneous forced expiratory flow where $\mathrm{X} \%$ of the FVC remains to be expired

MFVL Maximum flow-volume loop

mg Milligrams

MIF Maximal inspiratory flow

mL Millilitres

mm Millimetres

MMEF Maximum mid-expiratory flow

ms Milliseconds

MVV Maximum voluntary ventilation

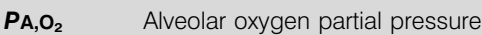

PB Barometric pressure

PEF Peak expiratory flow

$\mathbf{P H}_{2} \mathrm{O} \quad$ Water vapour partial pressure

$\mathbf{P I}_{1} \mathrm{O}_{2} \quad$ Inspired oxygen partial pressure

$\boldsymbol{\theta}$ (theta) Specific uptake of $\mathrm{CO}$ by the blood

RT Rise time from $10 \%$ to $90 \%$ of PEF

RV Residual volume

s Seconds

STPD Standard temperature $\left(273 \mathrm{~K}, 0^{\circ} \mathrm{C}\right)$, pressure $(101.3 \mathrm{kPa}$, $760 \mathrm{mmHg}$ ) and dry

TB Tuberculosis

TGV (or Thoracic gas volume

VTG)

$\boldsymbol{t}$ Time taken for inspiration

TLC Total lung capacity

Tr Tracer gas

tot Total time of respiratory cycle

TV (or VT) Tidal volume

VA Alveolar volume

VA,eff Effective alveolar volume

VC Vital capacity

Vc Pulmonary capillary blood volume

VD Dead space volume

Vı Inspired volume

Vs Volume of the expired sample gas

ug Micrograms 


\section{ACKNOWLEDGEMENTS}

R. Pellegrino: Azienda Ospedaliera S. Croce e Carle, Cuneo, Italy; G. Viegi: CNR Institute of Clinical Physiology, Pisa, Italy; V. Brusasco: Università degli Studi di Genova, Genova, Italy; R.O. Crapo and R. Jensen: LDS Hospital, Salt Lake City, UT, USA; F. Burgos: Hospital Clinic Villarroel, Barcelona, Spain; R. Casaburi: Harbor UCLA Medical Center, Torrance, CA, USA; A. Coates: Hospital for Sick Children, Toronto, ON, Canada; C.P.M. van der Grinten: University Hospital of Maastrict, Maastrict, the Netherlands; P. Gustafsson: Queen Silvias Children's Hospital, Gothenburg, Sweden; J. Hankinson: Hankinson Consulting, Inc., Valdosta, GA, USA; D.C. Johnson: Massachusetts General Hospital and Harvard Medical School, Boston, MA, USA; N. MacIntyre: Duke University Medical Center, Durham, NC, USA; R. McKay: Occupational Medicine, Cincinnati, OH, USA; M.R. Miller: University Hospital Birmingham NHS Trust, Birmingham, UK; D. Navajas: Lab Biofisica I Bioenginyeria, Barcelona, Spain; O.F. Pedersen: University of Aarhus, Aarhus, Denmark; J. Wanger: Pharmaceutical Research Associates, Inc., Lenexa, KS, USA.

\section{REFERENCES}

1 Miller MR, Crapo R, Hankinson J, et al. General considerations for lung function testing. Eur Respir J 2005; 26: 153-161.

2 Miller MR, Hankinson J, Brusasco V, et al. Standardisation of spirometry. Eur Respir J 2005; 26: 319-338.

3 Wanger J, Clausen JL, Coates A, et al. Standardisation of the measurement of lung volumes. Eur Respir J 2005; 26: 511-522.

4 MacIntyre N, Crapo RO, Viegi G, et al. Standardisation of the single-breath determination of carbon monoxide uptake in the lung. Eur Respir J 2005; 26: 720-735.

5 American Thoracic Society. Lung Function Testing: Selection of Reference Values and Interpretative Strategies. Am Rev Respir Dis 1991; 144: 1202-1218.

6 Solberg HE, Grasbeck R. Reference values. Adv Clin Chem 1989; 27: 1-79.

7 Stocks J, Quanjer PH. Reference values for residual volume, functional residual capacity and total lung capacity. Eur Respir J 1995; 8: 492-506.

8 Quanjer PH, Tammeling GJ, Cotes JE, Pedersen OF, Peslin R, Yernault JC. Lung volumes and forced ventilatory flows. Report Working Party Standardization of Lung Function Tests, European Community for Steel and Coal. Official Statement of the European Respiratory Society. Eur Respir J 1993; 6: Suppl. 16, 5-40.

9 Lohman TG, Roche AF, Martorell R, eds. Anthropometric standardization reference manual. Human Kinetics Books 1988; pp. 1-55.

10 Aggarwal AN, Gupta D, Jindal SK. Interpreting spirometric data: impact of substitution of arm span for standing height in adults from North India. Chest 1999; 115: 557-562.

11 Parker JM, Dillard TA, Phillips YY. Arm span-height relationships in patients referred for spirometry. Am J Respir Crit Care Med 1996; 154: 533-536.
12 Hankinson JL, Odencratz JR, Fedan KB. Spirometric reference values from a sample of the general US population. Am J Respir Crit Care Med 1999; 159: 179-187.

13 Korotzer B, Ong S, Hansen JE. Ethnic differences in pulmonary function in healthy nonsmoking AsianAmericans and European-Americans. Am J Respir Crit Care Med 2000; 161: 1101-1108.

14 Sharp DS, Enright PL, Chiu D, Burchfiel CM, Rodriguez BL, Curb JD. Reference values for pulmonary function tests of Japanese-American men aged 71-90 years. Am J Respir Crit Care Med 1996; 153: 805-811.

15 Harik-Khan RI, Fleg JL, Muller DC, Wise RA. The effect of anthropometric and socioeconomic factors on the racial difference in lung function. Am J Respir Crit Care Med 2002; 164: 1647-1654.

16 Roca J, Burgos F, Sunyer J, et al. References values for forced spirometry. Group of the European Community Respiratory Health Survey. Eur Respir J 1998; 11: 1354-1362.

17 Langhammer A, Johnsen R, Gulsvik A, Holmen TL, Bjermer L. Forced spirometry reference values for Norwegian adults: the Bronchial Obstruction in NordTrondelag study. Eur Respir J 2001; 18: 770-779.

18 Jensen RL, Crapo RO, Flint AK, Howell HM. Problems in selecting representative reference values for spirometry. Am J Respir Crit Care Med 2002; 165: A200.

19 Hardie JA, Buist AS, Vollmer WM, Ellingsen I, Bakke PS, Morkve O. Risk of over-diagnosis of COPD in asymptomatic elderly never-smokers. Eur Respir J 2002; 20: 1117-1122.

20 Quanjer PH. Standardized Lung Function Testing. Bull Eur Physiopathol 1983; 19: Suppl. 5, 22-27.

21 American Thoracic Society. Standardization of Spirometry: 1994 update. Am J Respir Crit Care Med 1995; 152: 1107-1136.

22 Enright PL, Kronmal RA, Higgins M, Schenker M, Haponik EF. Spirometry reference values for women and men 65 to 85 years of age. Cardiovascular health study. Am Rev Respir Dis 1993; 147: 125-133.

23 Glindmeyer HW, Lefante JJ, McColloster C, Jones RN, Weill H. Blue-collar normative spirometric values for Caucasian and African-American men and women aged 18 to 65. Am J Respir Crit Care Med 1995; 151: 412-422.

24 Sherrill DL, Lebowitz MD, Knudson RJ, Burrows B. Methodology for generating continuous prediction equations for pulmonary function measures. Comput Biomed Res 1991; 24: 249-260.

25 Burrows B, Lebowitz MD, Camilli AE, Knudson RJ. Longitudinal changes in forced expiratory volume in one second in adults. Methodologic considerations and findings in healthy nonsmokers. Am Rev Respir Dis 1986; 133: 974-980.

26 Ware JH, Dockery DW, Louis TA, Xu XP, Ferris BG Jr, Speizer FE. Longitudinal and cross-sectional estimates of pulmonary function decline in never-smoking adults. Am J Epidemiol 1990; 132: 685-700.

27 Sherrill DL, Lebowitz MD, Knudson RJ, Burrows B. Continuous longitudinal regression equations for pulmonary function measures. Eur Respir J 1992; 5: $452-462$. 
28 Pistelli F, Bottai M, Viegi G, et al. Smooth reference equations for slow vital capacity and flow-volume curve indexes. Am J Respir Crit Care Med 2000; 161: 899-905.

29 Wang X, Dockery DW, Wypij D, Fay ME, Ferris BG Jr. Pulmonary function between 6 and 18 years of age. Pediatr Pulmonol 1993; 15: 75-88.

30 Quanjer PH, Stocks J, Polgar G, Wise M, Karlberg J, Borsboom G. Compilation of reference values for lung function measurements in children. Eur Respir J 1989; 1: Suppl. 4, 184S-261S.

31 Degroodt EG, Quanjer PH, Wise ME, Van Zomeren BC. Changing relationships between stature and lung volumes during puberty. Respir Physiol 1986; 65: 139-153.

32 Borsboom GJ, van Pelt W, Quanjer PH. Pubertal growth curves of ventilatory function: Relationship with childhood respiratory symptoms. Am Rev Respir Dis 1993; 147: 372-378.

33 Cotes JE. Lung Function. In: Cotes JE, ed. Differences between Ethnic Groups: Assessment and Application in Medicine. 5th Edn. Oxford, Blackwell Scientific Publications, 1993; 474-482.

34 Yang TS, Peat J, Keena V, Donnelly PM, Unger W, Woolcock A. A review of the racial differences in the lung function of normal Caucasian, Chinese and Indian subjects. Eur Respir J 1991; 4: 872-880.

35 Lapp NL, Amandus HE, Hall R, Morgan WK. Lung volumes and flow rates in black and white subjects. Thorax 1974; 29: 185-188.

36 Lanese RR, Keller MD, Foley MF, Underwood EH. Differences in pulmonary function tests among whites, blacks, and American Indians in a textile company. J Occup Med 1978; 20: 39-44.

37 Gaultier C, Crapo RO. Effects of nutrition, growth hormone disturbances, training, altitude, and sleep on lung volumes. Eur Respir J 1997; 10: 2913-2919.

38 Cotes JE, Chinn DJ, Quanjer PhH, Roca J, Yernault JC. Standardization of the measurement of transfer factor (diffusing capacity). Report Working Party Standardization of Lung Function Tests, European Community for Steel and Coal. Official Statement of the European Respiratory Society. Eur Respir J 1993; 6: Suppl. 16, 41-52.

39 American Thoracic Society. Single breath carbon monoxide diffusing capacity (transfer factor). Recommendations for a standard technique - 1995 Update. Am J Respir Crit Care Med 1995; 152: 2185-2198.

40 Crapo RO, Morris AH. Standardized single-breath normal values for carbon monoxide diffusing capacity. Am Rev Respir Dis 1981; 123: 185-189.

41 Cotes JE, Hall AM. The transfer factor for the lung: normal values in adults. In: Arcangeli $\mathrm{P}$, Cotes JE, Cournand A, eds. Introduction to the definition of normal values for respiratory function in man. Panminerva Medica, Torino, 1970; pp. 327-343.

42 Paoletti P, Viegi G, Pistelli G, et al. Reference equations for the single-breath diffusing capacity. A cross-sectional analysis and effect of body size and age. Am Rev Respir Dis 1985; 132: 806-813.

43 Roca J, Rodriguez-Roisin R, Cobo E, Burgos F, Perez J, Clausen JL. Single-breath carbon monoxide diffusing capacity prediction equations from a Mediterranean population. Am Rev Respir Dis 1990; 141: 1026-1032.
44 Griner PF, Mayewsky RJ, Mushlin AI, Greenland P. Selection and interpretation of diagnostic tests and procedures: principles and applications. Ann Intern Med 1981; 94 (part 2): 557-592.

45 Bates DV. Respiratory Function in Disease. 3rd edn. Philadelphia, WB Saunders, 1989.

46 Wilson AF, ed. Pulmonary Function Testing, Indications and Interpretations. Orlando, Grune \& Stratton, 1985.

47 Pride NB, Macklem PT. Lung mechanics in disease. In: Macklem PT, Mead J, eds. Handbook of Physiology. The Respiratory System. Mechanics of Breathing. Section 3, Vol. III, part 2. Bethesda, American Physiological Society, 1986; pp 659-692.

48 Flenley DC. Chronic obstructive pulmonary disease. Dis Mon 1988; 34: 537-599.

49 Olive JT, Hyatt RE. Maximal expiratory flow and total respiratory resistance during induced bronchoconstriction in asthmatic subjects. Am Rev Respir Dis 1972; 106: 366-376.

50 Hyatt RE, Okeson GC, Rodarte JR. Influence of expiratory flow limitation on the pattern of lung emptying in man. $J$ Appl Physiol 1973; 35: 411-419.

51 Rodarte JR, Hyatt RE, Cortese DA. Influence of expiratory flow on closing capacity at low expiratory flow rates. J Appl Physiol 1975; 39: 60-65.

52 Guerry-Force ML, Müller NL, Wright JL, Wiggs B, Coppin C, Paré PD, Hogg JC. A comparison of bronchitis obliterans with organizing pneumonia, usual interstitial pneumonia, and small airways disease. Am Rev Respir Dis 1987; 135: 705-712.

53 Aaron SD, Dales RE, Cardinal P. How accurate is spirometry at predicting restrictive impairment. Chest 1999; 115: 869-873.

54 Glady CA, Aaron SD, Lunau M, Clinch J, Dales RE. A spirometry-based algorithm to direct lung function testing in the pulmonary function laboratory. Chest 2003; 123: 1939-1946.

55 Rodenstein DO, Stanescu DC. Reassessment of lung volume measurement by helium dilution and body plethysmography in COPD. Am Rev Respir Dis 1983; 128: 54-59.

56 Ferris BG. Epidemiology standardization project (American Thoracic Society). Am Rev Respir Dis 1978; 118: 1-120.

57 Punjabi NM, Shade D, Wise RA. Correction of singlebreath helium lung volumes in patients with airflow obstruction. Chest 1998; 114: 907-918.

58 Dykstra BJ, Scanlon PD, Kester MM, Beck KC, Enright PL. Lung volumes in 4774 patients with obstructive lung disease. Chest 1999; 115: 68-74.

59 Pauwels RA, Buist AS, Calverley PM, Jenkins CR, Hurd SS, GOLD Scientific Committee. Global strategy for the diagnosis, management, and prevention of chronic obstructive pulmonary disease. NHLBI/WHO Global Initiative for Chronic Obstructive Lung Disease (GOLD) Workshop summary. Am J Respir Crit Care Med 2001; 163: 1256-1276.

60 Celli BR, MacNee W, and committe members. Standard for the diagnosis and treatment of patients with COPD: a summary of the ATS/ERS position paper. Eur Respir J 2004; 23: 932-946. 
61 Brusasco V, Pellegrino R, Rodarte JR. Vital capacities in acute and chronic airway obstruction. Dependence on flow and volume histories. Eur Respir J 1997; 10: 1316-1320.

62 Celli BR, Halbert RJ, Isonaka S, Schau B. Population impact of different definition of airway obstruction. Eur Respir J 2003; 22: 268-273.

63 American Thoracic Society. Idiopathic pulmonary fibrosis: diagnosis and treatment. International consensus statement. Am J Respir Crit Care Med 2000; 161: 646-664.

64 Vedal S, Crapo RO. False positive rates of multiple pulmonary function tests in healthy subjects. Bull Eur Physiopathol Respir 1983; 19: 263-266.

65 Knudson RJ, Burrows B, Lebowitz MD. The maximal expiratory flow-volume curve: its use in the detection of ventilatory abnormalities in a population study. Am Rev Respir Dis 1976; 114: 871-879.

66 Mannino DM, Buist AS, Petty TL, Enright PL, Redd SC. Lung function and mortality in the United States: data from the first National Health and Nutrition Examination Survey follow-up. Thorax 2003; 58: 388-393.

67 Hyatt RE. Forced expiration. In: Macklem PT, Mead J, eds. Handbook of Physiology. The Respiratory System. Mechanics of breathing. Section 3, Vol. III, part 2. Bethesda, American Physiological Society, 1986; pp. 295-314.

68 Coates AL, Boyce P, Shaw DG, Godfrey S, Mearns M. The relationship between the chest radiograph, regional lung function studies, exercise tolerance, and clinical condition in children with cystic fibrosis. Arch Dis Child 1981; 56: 106-111.

69 Kerem E, Reisman JJ, Corey ML, Canny GJ, Levison H. Prediction of mortality in patients with cystic fibrosis. $N$ Engl J Med 1992; 326: 1187-1191.

70 Anthonisen NR. Tests of mechanical function. In: Macklem PT, Mead J, eds. Handbook of Physiology. The Respiratory System. Mechanics of breathing. Section 3, Vol. III, part 2. Bethesda, American Physiological Society, 1986; pp. 753-784.

71 Braun NMT, Arora NS, Rochester DF. Respiratory muscle and pulmonary function in polymyositis and other proximal myopathies. Thorax 1983; 38: 616-623.

72 Serisier DE, Mastaglia FL, Gibson GJ. Respiratory muscle function and ventilatory control, I in patients with motor neurone disease, II in patients with myotonic dystrophy. Q J Med 1982; 51: 205-226.

73 Engstrom H, Grimby G, Soderholm B. Dynamic spirometry in patients with tracheal stenosis. Acta Med Scand 1964; 176: 329-334.

74 Wasserman K, Hansen JE, Sue DY, Whipp BJ. Principles of Exercise Testing and Interpretation. Philadephia, Lea \& Fabiger, 1987; pp. 72-86.

75 Babb TG, Viggiano R, Hurley B, Staats B, Rodarte JR. Effect of mild-to-moderate airflow limitation on exercise capacity. J Appl Physiol 1991; 70: 223-230.

76 Pellegrino R, Villosio C, Milanese U, Garelli G, Rodarte JR, Brusasco V. Breathing during exercise in subjects with mild to moderate airflow obstruction. J Appl Physiol 1999; 87: 1697-1704.

77 American Thoracic Society. Evaluation of impairment/ disability secondary to respiratory disorders. Am Rev Respir Dis 1986; 133: 1205-1209.
78 American Medical Association. Guides to the Evaluation of Permanent Impairment. Edn 4. Chicago (IL), USA, American Medical Association, 1995.

79 Becklake MR, Kalica AR. NHLBI workshop summary. Scientific issues in the assessment of respiratory impairment. Am Rev Respir Dis 1988; 137: 1505-1510.

80 Kanner RE, Renzetti AD, Stanish WM, Barkman HW, Klauber MR. Predictors of survival in subjects with chronic airflow limitation. Am J Med 1983; 74: 249-255.

81 Traver GA, Cline MG, Burrows B. Predictors of mortality in chronic obstructive pulmonary disease. Am Rev Respir Dis 1979; 119: 895-902.

82 Anthonisen NR, Wright EC, Hodgkin JE. Prognosis in chronic obstructive pulmonary disease. Am Rev Respir Dis 1986; 133: 14-20.

83 American Thoracic Society. Guidelines for the evaluation of impairment/disability in patients with asthma. Am Rev Respir Dis 1993; 147: 1056-1061.

84 Kannel WB, Lew EA. Vital capacity as a predictor of cardiovascular disease: the Framingham study. Am Hearth J 1983; 105: 311-315.

85 Kannel WB, Lew EA, Hubert HB, Castelli WP. The value of measuring vital capacity for prognostic purposes. Trans Assoc Life Insur Med Dir Am 1981; 64: 66-83.

86 Tockman MS, Comstock GW. Respiratory risk factors and mortality: longitudinal studies in Washington county, Maryland. Am Rev Respir Dis 1989; 140: S56-S63.

87 Foxman B, Higgins ITT, Oh MS. The effects of occupation and smoking on respiratory disease mortality. Am Rev Respir Dis 1986; 134: 649-652.

88 Annesi I, Kauffmann F. Is respiratory mucus hypersecretion really an innocent disorder? Am Rev Respir Dis 1986; 134: 688-693.

89 Ortmeyer CE, Costello J, Morgan WKC, Swecker S, Peterson M. The mortality of Appalachian coal miners 1963 to 1971. Arch Environ Health 1974; 29: 67-72.

90 Peto R, Speizer FE, Cochrane AL, et al. The relevance in adults of air-flow obstruction, but not of mucus hypersecretion, to mortality from chronic lung disease; results from 20 years of prospective observation. Am Rev Respir Dis 1983; 128: 491-500.

91 Neas LM, Schwartz J. Pulmonary function levels as predictors of mortality in a national sample of US adults. Am J Epidemiol 1998; 147: 1011-1018.

92 Ferguson MK, Little L, Rizzo L, et al. Diffusing capacity predicts morbidity and mortality after pulmonary resection. J Thorac Cardiovasc Surg 1988; 96: 894-900.

93 Black LF, Hyatt RE. Maximal static respiratory pressures in generalized neuromuscular disease. Am Rev Respir Dis 1971; 103: 641-650.

94 Fairshter RD. Airway hysteresis in normal subjects and individuals with chronic airflow obstruction. J Appl Physiol 1985; 58: 1505-1510.

95 Zamel N, Hughes D, Levison H, Fairshter RD, Gelb AF. Partial and complete maximum expiratory flow-volume curves in asthmatic patients with spontaneous bronchospasm. Chest 1983; 83: 35-39.

96 Burns CB, Taylor WR, Ingram RH Jr. Effects of deep inhalation in asthma: relative airway and parenchymal hysteresis. J Appl Physiol 1985; 59: 1590-1596. 
97 Brusasco V, Pellegrino R, Violante B, Crimi E. Relationship between quasi-static pulmonary hysteresis and maximal airway narrowing in humans. J Appl Physiol 1992; 72: 2075-2080.

98 Pellegrino R, Wilson O, Jenouri G, Rodarte JR. Lung mechanics during bronchoconstriction. J Appl Physiol 1996; 81: 964-975.

99 Koulouris NG, Valta P, Lavoie A, Corbeil C, Chasse M, Braidy J, Milic-Emili J. A simple method to detect expiratory flow limitation during spontaneous breathing. Eur Respir J 1995; 8: 306-313.

100 Eltayara L, Becklake MR, Volta CA, Milic-Emili J. Relationship between chronic dyspnea and expiratory flow limitation in patients with chronic obstructive pulmonary disease. Am J Respir Crit Care Med 1996; 154: 1726-1734.

101 Pellegrino R, Rodarte JR, Brusasco V. Assessing the reversibility of airway obstruction. Chest 1998; 114: 1607-1612.

102 Pellegrino R, Brusasco V. Lung hyperinflation and flow limitation in chronic airway obstruction. Eur Respir J 1997; 10: 543-549.

103 Pellegrino R, Brusasco V. On the causes of lung hyperinflation during bronchoconstriction. Review. Eur Respir J 1997; 10: 468-475.

104 Fessler HE, Scharf SM, Permutt S. Improvement in spirometry following lung volume reduction surgery. Application of a physiological model. Am J Respir Crit Care Med 2002; 165: 34-40.

105 Casanova C, Cote C, de Torres JP, et al. Inspiratory-tototal lung capacity ratio predicts mortality in patients with chronic obstructive pulmonary disease. Am J Respir Crit Care Med 2005; 171: 591-597.

106 Stark-Leyva KN, Beck KC, Johnson BD. Influence of expiratory loading and hyperinflation on cardiac output during exercise. J Appl Physiol 2004; 96: 1920-1927.

107 Guyatt GH, Townsend M, Nogradi S, Pugsley SO, Keller JL, Newhouse MT. Acute response to bronchodilator, an imperfect guide for bronchodilator therapy in chronic airflow limitation. Arch Intern Med 1988; 148: 1949-1952.

108 Lorber DB, Kaltenborn W, Burrows B. Responses to isoproterenol in a general population sample. Am Rev Respir Dis 1978; 118: 855-861.

109 Dales RE, Spitzer WO, Tousignant P, Schechter M, Suissa S. Clinical interpretation of airway response to a bronchodilator: epidemiologic considerations. Am Rev Respir Dis 1988; 138: 317-320.

110 Watanabe S, Renzetti AD Jr, Begin R, Bigler AH. Airway responsiveness to a bronchodilator aerosol. Am Rev Respir Dis 1974; 109: 530-537.

111 Anthonisen NR, Wright EC, the IPPB Trial group. Bronchodilator response in chronic obstructive pulmonary disease. Am Rev Respir Dis 1986; 133: 814-819.

112 Sourk RL, Nugent KM. Bronchodilator testing: confidence intervals derived from placebo inhalations. Am Rev Respir Dis 1983; 128: 153-157.

113 Tweddale PM, Alexander F, McHardy GJR. Short term variability in FEV1 and bronchodilator responsiveness in patients with obstructive ventilatory defects. Thorax 1987; 42: 487-490.
114 Eliasson O, Degraff AC Jr. The use of criteria for reversibility and obstruction to define patient groups for bronchodilator trials: influence of clinical diagnosis, spirometric and anthropometric values. Am Rev Respir Dis 1985; 132: 858-864.

115 Brand PL, Quanjer PhH, Postma DS, et al. Interpretation of bronchodilator response in patients with obstructive airways disease. Thorax 1992; 47: 429-436.

116 Olsen CR, Hale FC. A method for interpreting acute response to bronchodilators from the spirogram. Am Rev Respir Dis 1968; 98: 301-302.

117 Boggs PB, Bhat KD, Velovius WA, Debo MS. The clinical significance of volume adjusted maximal mid expiratory flow (iso-volume FEF25-75\%) in assessing airway responsiveness to inhaled bronchodilator in asthmatics. Ann Allergy 1982; 48: 139-142.

118 Redelmeier DA, Goldstein RS, Min ST, Hyland RH. Spirometry and dyspnea in patients with COPD. When small differences mean little. Chest 1996; 109: 1163-1168.

119 Barnes PJ, Gribbin HR, Osmanliev D, Pride NB. Partial flow-volume curves to measure bronchodilator doseresponse curves in normal humans. J Appl Physiol 1981; 50: 1193-1197.

120 Wang JW, McFadden ER, Ingram RH Jr. Effects of increasing doses of $\beta$-agonists on airway and parenchymal hysteresis. J Appl Physiol 1990; 68: 363-368.

121 Berry RB, Fairshter RD. Partial and maximal expiratory flow-volume curves in normal and asthmatic subjects before and after inhalation of metaproterenol. Chest 1985; 88: 697-702.

122 O'Donnell DE. Assessment of bronchodilator efficacy in symptomatic COPD. Is spirometry useful? Chest 2000; 117: 42S-47S.

123 O'Donnell DE, Lam M, Webb KA. Spirometric correlates of improvement in exercise performance after cholinergic therapy in chronic obstructive pulmonary disease. Am J Respir Crit Care Med 1999; 160: 542-549.

124 Cerveri I, Pellegrino R, Dore $\mathrm{R}$, et al. Mechanisms for isolated volume response to a bronchodilator in patients with COPD. J Appl Physiol 2000; 88: 1989-1995.

125 Empey DW. Assessment of upper airways obstruction. BMJ 1972; 3: 503-505.

126 Miller MR, Pincock AC, Oates GD, Wilkinson R, SkeneSmith H. Upper airway obstruction due to goitre: detection, prevalence and results of surgical management. Q J Med 1990; 74: 177-188.

127 Miller RD, Hyatt RE. Obstructing lesions of the larynx and trachea. Mayo Clin Proc 1969; 44: 145-161.

128 Pedersen OF, Ingram RH Jr. Configuration of maximum expiratory flow-volume curve: model experiments with physiological implications. J Appl Physiol 1985; 58: 1305-1313.

129 Miller MR, Pedersen OF. Peak flow meter resistance decreases peak expiratory flow in subjects with COPD. $J$ Appl Physiol 2000; 89: 283-290.

130 Gibson GJ. Central airway obstruction. In: Clinical Tests of Respiratory Function. 2nd edn. London, Chapman\&Hall, 1996; pp. 194-202.

131 Lebowitz MD, Quackenboss J, Camilli AE, Bronnimann D, Holberg CJ, Boyer B. The epidemiological importance of 
intraindividual changes in objective pulmonary responses. Eur J Epidemiol 1987; 3: 390-398.

132 Kangalee KM, Abboud RT. Interlaboratory and intralaboratory variability in pulmonary function testing: a 13 year study using a normal biologic control. Chest 1992; 101: 88-92.

133 Frey TM, Crapo RO, Jensen RL, Elliott CG. Diurnal variation of the diffusing capacity of the lung: is it real? Am Rev Respir Dis 1987; 136: 1381-1384.

134 Hankinson JL, Stocks J, Peslin R. Reproducibility of lung volume measurements. Eur Respir J 1998; 11: 787-790.

135 Bland M. Repeatability and precision in measurement. An Introduction to Medical Statistics, Oxford Medical Publications, 1987; pp. 276-278.

136 Robson AG, Innes JA. Short-term variability of singlebreath carbon monoxide transfer factor. Thorax 2001; 56: 358-361.

137 Spencer DA, Marshall T, Weller PH, Williams J. A superior method of assessing the reproducibility of pulmonary function measurements. Am Rev Respir Dis 1992; 145: A253.

138 Collard HR, King TE Jr, Bartelson BB, Vourlekis JS, Schwarz MI, Brown KR. Changes in clinical and physiological variables predict survival in pulmonary fibrosis. Am J Respir Crit Care Med 2003; 168: 538-542.

139 Hathaway EH, Tashkin DP, Simmons MS. Intraindividual variability in serial measurements of DLCO and alveolar volume over one year in eight healthy subjects using three independent measuring systems. Am Rev Respir Med 1989; 140: 1818-1822.

140 Wells AU, Desai SR, Rubens MB, et al. Idiopathic Pulmonary Fibrosis. A composite physiologic index derived from disease extent observed by computed tomography. Am J Respir Crit Care Med 2003; 167: 962-969.

141 Gibson GJ, Prescott RJ, Muers MF, et al. British Thoracic Society sarcoidosis study: effects of long-term corticosteroid therapy. Thorax 1996; 51: 238-247.

142 King TE Jr, Tooze JA, Schwarz MI, Brown KR, Cherniack RM. Predicting survival in Idiopathic Pulmonary Fibrosis. Scoring system and survival model. Am J Respir Crit Care Med 2001; 164: 1171-1181.

143 ACOEM Position Statement: Spirometry in the Occupational Setting. J Occup Environ Med 2000; 42: 228-245.

144 Hughes JM, Bates DV. Historical review: the carbon monoxide diffusing capacity (DLCO) and its membrane (DM) and red cell (Theta.Vc) components. Respir Physiol Neurobiol 2003; 138: 115-142.
145 Hughes JM. The single breath transfer factor $(T \mathrm{~L}, \mathrm{CO})$ and the transfer coefficient (KCO): a window onto the pulmonary microcirculation. Clin Physiol Funct Imaging 2003; 23: 63-71.

146 McLean A, Warren PM, Gillooly M, MacNee W, Lamb D. Microscopic and macroscopic measurements of emphysema: relation to carbon monoxide gas transfer. Thorax 1992; 47: 144-149.

147 Kitaichi M, Nishimura K, Itoh H, Izumi T. Pulmonary lymphangioleiomyomatosis: a report of 46 patients including a clinicopathologic study of prognostic factors. Am J Respir Crit Care Med 1995; 151: 527-533.

148 Bernstein RJ, Ford RL, Clausen JL, Moser KM. Membrane diffusion and capillary blood volume in chronic thromboembolic pulmonary hypertension. Chest 1996; 110: 1430-1436.

149 Horn M, Ries A, Neveu C, Moser K. Restrictive ventilatory pattern in precapillary pulmonary hypertension. Am Rev Respir Dis 1983; 128: 163-165.

150 Collard P, Njinou B, Nejadnik B, Keyeux A, Frans A. DLCO in stable asthma. Chest 1994; 105: 1426-1429.

151 Collard P, Wilputte JY, Aubert G, Rodenstein DO, Frans A. The DLCO in obstructive sleep apnea and obesity. Chest 1996; 110: 1189-1193.

152 Greening AP, Hughes JMB. Serial estimations of DLCO in intrapulmonary hemorrhage. Clin Sci 1981; 60: 507-512.

153 Hughes JM, Pride NB. In defence of the carbon monoxide transfer coefficient KCO (TL/Va). Eur Respir J 2001; 17: 168-174.

154 Kanengiser LC, Rapoport DM, Epstein H, Goldring RM. Volume adjustment of mechanics and diffusion in interstitial lung disease: lack of clinical relevance. Chest 1989; 96: 1036-1042.

155 Stam H, Splinter TAW, Versprille A. Evaluation of diffusing capacity in patients with a restrictive lung disease. Chest 2000; 117: 752-757.

156 Frans A, Nemery B, Veriter C, Lacquet L, Francis C. Effect of alveolar volume on the interpretation of single-breath DLCO. Respir Med 1997; 91: 263-273.

157 Chinet T, Jaubert F, Dusser D, Danel C, Chretien J, Huchon GJ. Effects of inflammation and fibrosis on pulmonary function in diffuse lung fibrosis. Thorax 1990; 45: 675-678.

158 Johnson DC. Importance of adjusting DLCO and KCO for alveolar volume. Respir Med 2000; 94: 28-37.

159 Chinn DJ, Cotes JE, Flowers R, Marks AM, Reed JW. Transfer factor (diffusing capacity) standardized for alveolar volume: validation, reference values and applications of a new linear model to replace KCO (TL/VA). Eur Respir J 1996; 9: 1269-1277. 